\title{
Influence of turbidity and aeration on the albedo of mountain streams
}

\author{
by \\ Alexander D. McMahon \\ B.Sc., Geography, Appalachian State University, 2014 \\ A THESIS SUBMITTED IN PARTIAL FULFILLMENT \\ OF THE REQUIREMENTS FOR THE DEGREE OF \\ Master of Science \\ in \\ THE FACULTY OF GRADUATE AND POSTDOCTORAL STUDIES \\ (Geography) \\ The University of British Columbia \\ (Vancouver) \\ August 2016 \\ (C) Alexander D. McMahon, 2016
}




\section{Abstract}

Stream surface albedo plays a key role in the energy balance of rivers and streams that are exposed to direct solar radiation. Most physically based models assume that stream albedo lies between 0.03 and 0.10 , based primarily on measurements from low-gradient streams with low suspended sediment concentrations. Albedo should depend upon solar elevation angle, suspended sediment, aeration, and fraction of direct vs diffuse radiation. However, there is no model available for predicting the dependence of albedo on these factors. This study quantified the dependence of albedo of mountain streams on the controlling factors in order to improve the representation of albedo in energy balance studies. Proxy measures for albedo using digital camera imagery were also developed and assessed.

Stream surface albedo was measured at nine sites with a variety of gradients and suspended sediment characteristics in the southern Coast Mountains of British Columbia, Canada. As expected, albedo of low-gradient, non-whitewater (flatwater) streams increased with solar zenith angle, suspended sediment concentration, and proportion of diffuse to direct solar radiation, ranging between 0.025 during cloudy periods in clear water to 0.25 for turbid water at zenith angles of less than 20 degrees. Albedo varied with discharge in steep reaches or at channel steps and cascades where flow was visibly aerated, with a range of 0.09 to 0.33 . In clear weather, albedo exhibited notable diurnal variability at flatwater sampling sites. For example, during late summer, surface albedo typically fluctuated between 0.08 and 0.15 on a diurnal basis at a flatwater site on the highly turbid, glacier-fed Lillooet River. Physically based representations of albedo should be incorporated into energy balance models in order to improve predictions of stream temperature, especially for future scenarios. 


\section{Preface}

This thesis is original work completed by the author. Guidance was given by the supervisory committee: Dan Moore, Brett Eaton, and Ian McKendry. A version of this work has been delivered as a presentation (McMahon, A. \& Moore, R.D., Influence of turbidity and aeration on the albedo of mountain streams) on which the author acted as the lead investigator, composing and delivering the presentation at the 2016 Canadian Meteorological and Oceanographic Society (CMOS) / Canadian Geophysical Union (CGU) Joint Assembly on June 2, 2016 in Fredericton, New Brunswick. 


\section{Table of Contents}

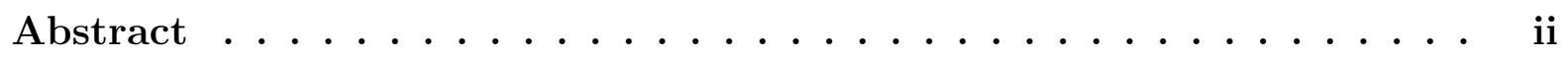

Preface $\ldots \ldots \ldots \ldots \ldots \ldots \ldots \ldots \ldots$ iii

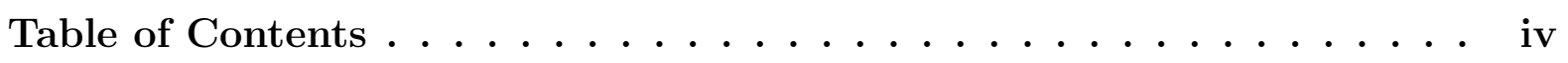

List of Tables $\ldots \ldots \ldots \ldots \ldots \ldots \ldots \ldots \ldots$ vi

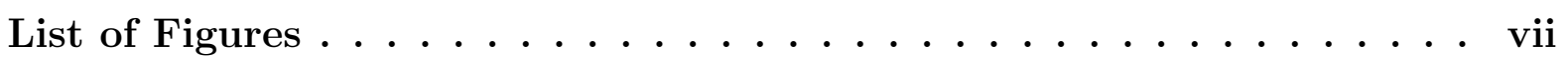

Acknowledgments ....................... viii

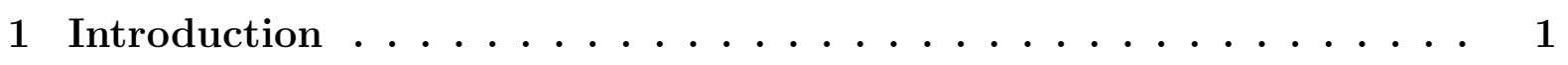

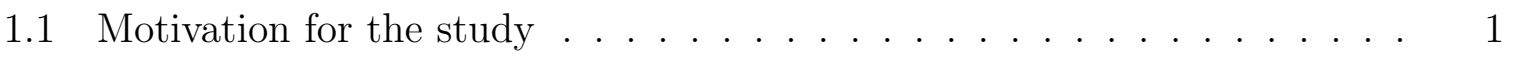

1.2 Variability of water surface albedo . . . . . . . . . . . . . 2

1.3 Albedo representation in energy balance studies . . . . . . . . . . . 4

1.4 Research objectives and thesis structure $\ldots \ldots \ldots \ldots$

2 Methods ............................ 6

2.1 Study area and field sites . . . . . . . . . . . . . . 6

2.2 Field methods . . . . . . . . . . . . . . . . . . . 9

2.2 .1 Suspended sediment $\ldots \ldots \ldots \ldots 11$

2.2 .2 Streamflow . . . . . . . . . . . . . . . . 11

2.2 .3 Digital camera imagery . . . . . . . . . . . . . . . . . . 12

2.2 .4 Reach characteristics . . . . . . . . . . . . . . . 12

2.3 Data analysis . . . . . . . . . . . . . . . . . . . 12

2.3.1 Pyranometer calibration . . . . . . . . . . . . . . 12

2.3.2 Albedo calculation . . . . . . . . . . . . . . . 13

2.3 .3 Solar position . . . . . . . . . . . . . . . . . 14

2.3 .4 Digital camera imagery . . . . . . . . . . . . . . 15 
2.3.5 Statistical modelling

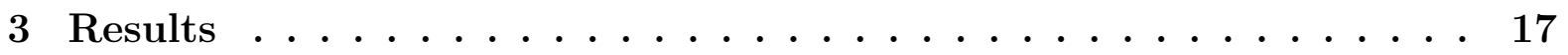

3.1 Overview of the study period $\ldots \ldots \ldots \ldots \ldots$

3.2 Pyranometer calibration . . . . . . . . . . . . . . . 20

3.3 Analysis of digital camera images . . . . . . . . . . . . . . 22

3.4 Exploratory analysis of albedo variability . . . . . . . . . . . . . . . 23

3.4.1 Relation with atmospheric transmissivity . . . . . . . . . . . 24

3.4.2 Relation with solar elevation angle . . . . . . . . . . . 25

3.4.3 Relation with suspended sediment . . . . . . . . . . . . 26

3.4.4 Relation with discharge and aeration . . . . . . . . . . 28

3.4.5 Recursive partitioning . . . . . . . . . . . . . . . 29

3.5 Statistical modelling . . . . . . . . . . . . . . . . . 32

3.5.1 Model fitting and cross validation . . . . . . . . . . . . . . 32

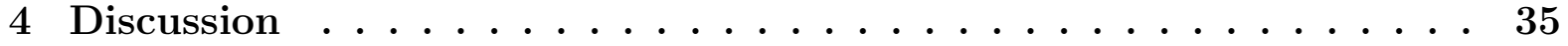

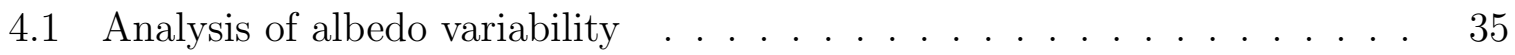

4.1.1 Solar angle and transmissivity . . . . . . . . . . . 35

4.1 .2 Discharge and aeration . . . . . . . . . . . . . 36

4.1 .3 Suspended sediment . . . . . . . . . . . . . . . . 37

4.2 Model performance . . . . . . . . . . . . . . . . . . . 38

4.2 .1 Model selection and testing . . . . . . . . . . . . . . 38

4.2 .2 Model scaling . . . . . . . . . . . . . . . . . . . . . . . 39

4.3 Analysis of digital camera images . . . . . . . . . . . . . . . . . . . 39

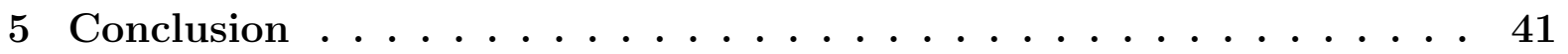

5.1 Key findings . . . . . . . . . . . . . . . . . . . . . . 41

5.2 Recommendations for future research . . . . . . . . . . . . . . 42

Bibliography . . . . . . . . . . . . . . . . . 44 


\section{List of Tables}

Table 1.1 Summary of stream surface albedo representations used by previous river energy balance studies. . . . . . . . . . . . . . 4

Table 2.1 Stream reaches used in the study. . . . . . . . . . . . . . . . 9

Table 3.1 Pyranometer calibration results . . . . . . . . . . . . . . . . . . 21

Table 3.2 Summary of albedo values for flatwater and whitewater subsets and relations with solar elevation angle, stratified by transmissivity $\ldots .25$

Table 3.3 Minumum, mean, and maximum $S S C$ values, mean flatwater albedo, and mean transmissivity observed for each reach . . . . . . . . 27

Table 3.4 Summary of model fitting for the flatwater subset using the categorical $S S C$ representation . . . . . . . . . . . . . .

Table 3.5 Summary of model fitting for the whitewater subset using the categorical $S S C$ representation . . . . . . . . . . . . . . . .

Table 3.6 Summary of model fitting for the flatwater subset using the logarithmic $S S C$ representation . . . . . . . . . . . . .

Table 3.7 Summary of model fitting for the flatwater subset using the logarithmic $S S C$ representation . . . . . . . . . . . . .

Table 3.8 Cross-validated $\mathrm{R}^{2}$ and RMSE for models selected during the initial stages of model fitting. . . . . . . . . . . . . . . . 


\section{List of Figures}

Figure 2.1 Sites used in the study $\ldots \ldots \ldots \ldots \ldots \ldots$

Figure 2.2 Map of the study area $\ldots \ldots \ldots \ldots$

Figure 2.3 Monitoring set-up used to measure albedo and obtain camera imagery 10

Figure 2.4 Sample albedo time series measurement . . . . . . . . . . . . . . . . . 13

Figure 3.1 Historical maximum, mean, and minimum monthly air temperatures and 2015 monthly mean air temperature measured near Pemberton. . 18

Figure 3.2 Historical mean monthly total precipitation and 2015 monthly total precipitation measured near Pemberton . . . . . . . . . . . . 19

Figure 3.3 Historical maximum, mean, and minimum daily streamflow and 2015 mean flow at the Lillooet River. . . . . . . . . . . . . . . . 20

Figure 3.4 Relation between uncalibrated CM3 output voltage and CM6B irradi-

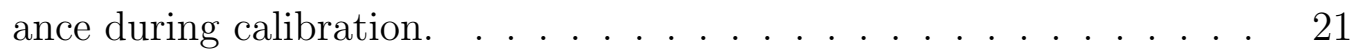

Figure 3.5 Relation between measured albedo and the coefficient of variation of pixel RGB values at Rutherford Creek . . . . . . . . . . . . . 23

Figure 3.6 Albedo as a function of atmospheric transmissivity . . . . . . . . 24

Figure 3.7 Albedo as a function of solar elevation angle. . . . . . . . . . . 26

Figure 3.8 Albedo as a function of SSC, plotted on log axes . . . . . . . . . . 27

Figure 3.9 Albedo as a function of $S S C$, plotted on linear axes . . . . . . . . 28

Figure 3.10 Albedo as a function of discharge at Rutherford Creek. . . . . . . . 29

Figure 3.11 Regression tree fit to the flatwater subset . . . . . . . . . . . 30

Figure 3.12 Regression tree fit to the whitewater albedo subset . . . . . . . . 31

Figure 3.13 Cross-validated predicted albedo values versus observed albedo for the flatwater and whitewater subsets. . . . . . . . . . . . 34 


\section{Acknowledgments}

This work was completed as a result of efforts from many people. First and foremost, my thanks go to my supervisor, Dan Moore. Dan's guidance, immeasurable enthusiasm, and patience were key to the successful completion of the project. I could not ask for a better supervisor.

Funding for this research was provided by operating grants to Professor Dan Moore from the Natural Sciences and Engineering Research Council (NSERC) of Canada.

Special thanks to Derek van der Kamp, Moritz Mährlein, Dave Reid, and Mark Richardson, whose technical expertise and guidance was instrumental to the collection and processing of data during the field season. I'd also like to thank all of people who provided field assistance: Eleri Harris, Cameron Hunter, Haven Jerreat-Poole, Moritz Mährlein, Nicholas McMahon, Mark Richardson, and Andras Szeitz.

Thanks to my undergraduate supervisor, Professor Baker Perry of Appalachian State University, whose teaching kindled my interest in the natural sciences. I would not be where I am today without his mentorship.

Finally, I would like to thank my family, who have always supported and encouraged me throughout my education. 


\section{Chapter 1}

\section{Introduction}

\subsection{Motivation for the study}

Water temperature governs a range of physical, biological, and chemical processes in streams, and plays a crucial role in the overall health of aquatic ecosystems (Coutant, 1999; Webb et al., 2008; Symonds and Moussalli, 2011). For example, water temperature influences fish mortality (Thomas et al., 1986), distribution (Hughes, 1998), growth and developmental rates (Shelbourn et al., 1973; Elliott and Hurley, 1997), pollutant uptake (Ficke et al., 2007), reproductive fitness (Fenkes et al., 2016), and competitive interactions (Reeves et al., 1987). In addition, dissolved oxygen solubility decreases at higher temperatures, while oxygen requirements for biological processes increase. Dissolved oxygen is a major determinant of aquatic habitat quality during the summer when the oxygen needs of aquatic organisms are highest and availability is at a minimum (Caissie, 2006).

Environmental changes and human activity can modify fluvial thermal regimes (Webb et al., 2008). Forest disturbance associated with wildfire and harvesting in riparian zones increase a stream's exposure to solar radiation, typically resulting in increases in summer water temperature (Moore et al., 2005). Reduction of streamflow associated with flow regulation and withdrawals increases the sensitivity of stream temperature to surface energy inputs by decreasing stream depth (Sinokrot and Gulliver, 2000). Additionally, dam releases may not be the same as downstream river temperature, providing another mechanism for altering water temperature (Olden and Naiman, 2010). Climate change can influence stream temperatures by influencing the timing and magnitude of streamflow as well as the surface energy exchanges (Meisner, 1990; Ficke et al., 2007; Isaak et al., 2010). 
Predictive models are often used to assist with designing and evaluating management options to minimize the effects of human activity on stream temperature - for example, for evaluating the sensitivity of stream temperature to flow reductions associated with withdrawals (Dymond, 1984; Bartholow, 1991). The most rigorous approach to modelling stream temperature is through the use of deterministic models that explicitly simulate surface energy exchanges, which include short- and longwave radiation and turbulent exchanges of sensible and latent heat (Sinokrot and Stefan, 1993; Caissie, 2006; Hannah et al., 2008). In streams that are exposed to direct sunlight, solar radiation is typically the dominant component of the energy balance during the summer (Moore et al., 2005).

Stream surface albedo - the fraction of incident solar radiation that is reflected - is typically not measured in stream temperature modelling studies. Some models, like HeatSource (Boyd and Kasper, 2003), compute albedo using a published function of solar incidence angle. Meier et al. (2003) accounted for variability in albedo in terms of solar zenith angle and cloud cover according to relations reported by Anderson (1954). Many modelling studies used an assumed fixed albedo. For example, a fixed value of 0.05 was assumed by Magnusson et al. (2012) in studies on proglacial channels. A lower fixed value of 0.03 was assumed by Caissie et al. (2007) for a pair of low-gradient rivers.

The overall objective of this study is to quantify the dependence of the albedo of mountain streams on the controlling factors to improve the representation of albedo in energy balance models. Progress in the subject will improve energy balance models and ultimately increase confidence in water temperature estimates that drive decision making in riparian and river management. The following section provides a review of the variability of water surface albedo based on both theory and measurements, and the final section summarizes the specific objectives of the study and the structure of the thesis.

\subsection{Variability of water surface albedo}

The Fresnel equations predict that reflectance of a light beam striking a surface increases at greater incidence angles (between the incident ray and the normal). At high solar altitudes under clear-sky conditions, albedo of the water surface is typically between 0.03 and 0.10 (Oke, 1987). At lower solar altitudes (greater incidence angles), however, values approaching 1.0 have been observed as the sun approaches $0^{\circ}$ (Nunez et al., 1972). Clouds and haze greatly enhance scattering of solar radiation, increasing the number of rays travelling at angles other than the solar elevation angle. At low solar elevation angles, this scattering increases the number of rays incident on the water surface at angles greater than the solar elevation angle, decreasing the amount of light reflected by the 
surface, consequently decreasing albedo. Conversely, scattered light increases albedo at high solar elevation angles, since a greater number of rays strike the water surface at decreased angles compared to the solar elevation angle (Katsaros et al., 1985).

Increased water surface roughness has a similar effect on reflectance. When the water surface is roughened and solar altitude is high, there is a higher probability that incident beams will be reflected off a sloping rather than horizontal surface, increasing surface albedo. At low solar altitudes, a rough water surface decreases albedo since beams would be more likely to encounter a raised slope rather than glancing off the surface (Oke, 1987).

The relation between albedo, solar elevation angle, and surface roughness has been quantified for lakes and oceans (e.g. Nunez et al., 1972; Payne, 1972; Katsaros et al., 1985; Jin et al., 2004). Payne (1972) measured ocean surface albedo values ranging between 0.03 at high sun angles to 0.45 for solar altitudes below $10^{\circ}$, although with considerable scatter for low sun angles. Using wind speed as a proxy for surface roughness, the effect of roughness was most pronounced at low solar angles. The negative albedosurface roughness relation was most pronounced at solar angles between 17 and $25^{\circ}$, whereas the positive relation at higher solar elevation angles was relatively small in comparison. Nunez et al. (1972) found that increasing wave height had a modest influence on albedo, except for solar altitude angles lower than $15^{\circ}$, when albedo was suppressed with increasing wave heights. Both studies found that the dependency between solar altitude and albedo decreases with increasing cloud cover, becoming undetectable during overcast conditions. Subsequent work has parameterized ocean surface albedo in terms of the driving physical processes with good predictive accuracy. For example, Jin et al. (2004) developed a parameterization of spectral and broadband albedo ocean surface based on solar zenith angle, wind speed, and ocean chlorophyll concentration, accounting for differences between direct and diffuse solar radiation components, achieving a model standard error of 0.014 .

The effects of suspended sediment and aeration on albedo have been examined by field and laboratory studies focused on the spectral reflectance of lake and ocean surfaces (e.g. Whitlock et al., 1982; Koepke, 1984). In a laboratory study, Han (1997) found that reflectance increased non-linearly in the visible spectrum as sediment was added, with the dependence of reflectance on $S S C$ decreasing at higher concentrations. At $S S C=500 \mathrm{mg} / \mathrm{L}$, reflectance was highest between 600 and $700 \mathrm{~nm}$, with $23 \%$ of natural sunlight being reflected. Whitlock et al. (1982) found in laboratory studies that the reflectance of dense foam with high aeration, consisting of multiple bubble layers, averaged approximately $50 \%$ in visible wavelengths. Koepke (1984) measured the albedo of foam 
patches on the ocean surface. Fresh foam patches measured $1 \mathrm{~s}$ after generation had an average spectral reflectance of $41 \%$, decaying to $16 \%$ after $10 \mathrm{~s}$. The average spectral reflectance of all foam patches was $22 \%$.

\subsection{Albedo representation in energy balance studies}

Table 1.1 provides a summary of measured stream surface albedo. Leach and Moore (2010) found that mean albedo was 0.05 over pools and glides, and 0.06 over riffles. Evans et al. (1998) reported a mean albedo of 0.07, although there was distinct diurnal variability in albedo attributed to the solar elevation angle. Monthly daily mean albedo values ranged between 0.06 in July and 0.08 in November due to the differences in average solar position between months. Neilson et al. (2009) measured albedo on a low gradient reach of the Virgin River, Utah, USA, for turbidities ranging from 2 to 440 nephelometric turbidity units $(N T U)$. Albedo was less than 0.10 when the river's turbidity was low, but was enhanced by 0.03 to 0.07 at higher levels of turbidity. Working on turbid proglacial streams, Knudson (2012) found that albedo was enhanced by $S S C$ and varied with solar zenith angle. For Lillooet River, albedo ranged from 0.08-0.13, compared to 0.05-0.10 measured on two tributary reaches. Chikita et al. (2010) reported a mean albedo of 0.1 for a proglacial stream with suspended sediment concentrations typically exceeding $200 \mathrm{mg} / \mathrm{L}$, with daily maxima greater than $500 \mathrm{mg} / \mathrm{L}$ (Kido et al., 2007).

Table 1.1: Summary of stream surface albedo representations used by previous river energy balance studies. NS indicates values were not specified.

\begin{tabular}{lllll}
\hline Study & Location & Albedo & Channel Gradient $S S C / N T U$ \\
\hline Evans et al. (1998) & Staffordshire, UK & 0.05 & NS; low gradient & NS; low $S S C$ \\
Hannah et al (2008) & Aberdeenshire, UK & NS & $3-15 \%$ & NS \\
Neilson et al. (2009) & Utah, USA & NS & $0.12-0.39 \%$ & $2-440 N T U$ \\
Chikita et al. (2010) & Alaska, USA & 0.1 & $2-30 \%$ & $>200 \mathrm{mg} / \mathrm{L}$ \\
Leach \& Moore (2010) & BC, CA & $0.05-0.06$ & $2.20 \%$ & NS; low SSC \\
Benyaha et al. (2011) & NB, CA & $0.01-0.05$ & NS; low gradient & NS \\
Richards \& Moore (2011) & BC, CA & $0.1-0.4$ & $26 \%$ & $60-100 \mathrm{mg} / \mathrm{L}$ \\
Knudson (2012) & BC, CA & $0.08-0.10$ & $0.60 \%$ & $34-831 \mathrm{mg} / \mathrm{L}$ \\
Khamis et al. (2015) & Cirque de Gavarnie, France NS & NS; high gradient & NS \\
\hline
\end{tabular}

Some work has found that stream surface albedo can be considerably higher than the typical 0.03-0.10 range. Working on a steep proglacial channel, Richards and Moore (2011) found that albedo ranged between 0.10 at low flows up to 0.40 at higher flows as the water surface became increasingly aerated. Albedo varied nonlinearly with discharge 
(a proxy for aeration), with an additional term to account for incoming solar radiation, which represents the combined effects of solar elevation angle and the direct fraction of solar radiation. The variable representation of albedo improved the prediction of net radiation at the site: the Nash-Sutcliffe efficiency of the radiation model was 0.81 using the variable albedo compared to 0.75 and 0.78 using fixed albedo values of 0.05 and 0.10 .

\subsection{Research objectives and thesis structure}

The review of the literature in section 1.2 indicates that stream surface albedo can deviate significantly from the typical range of values assumed in many stream temperature modelling studies, especially for turbid and/or aerated conditions. Both theory and observations indicate that albedo should depend on (a) angle of incidence, (b) fractions of direct vs diffuse solar radiation, (c) turbidity and (d) degree of aeration. However, there is currently no quantitative model available for predicting the dependence of stream surface albedo on these factors. The specific research objectives addressed by the thesis are:

1. to quantify the dependence of albedo on suspended sediment, solar position, fractions of direct vs diffuse radiation, and aeration for a sample of mountain streams that encompass a range of flow regimes, gradients, and channel morphologies;

2. to develop a statistical model to predict albedo that could be easily incorporated into energy balance models; and

3. to develop and assess the viability of proxy measures for albedo using digital camera imagery.

The remainder of the thesis is organized as follows. Chapter 2 describes the study area, field methods, and data analysis. Chapter 3 presents the results of the field work and data analysis. Chapter 4 describes how the results of this study address the research questions outlined previously. Chapter 5 summarizes the conclusions of the study and identifies areas where future research is necessary. 


\section{Chapter 2}

\section{Methods}

\subsection{Study area and field sites}

Research focused on nine streams in the southern Coast Mountains of British Columbia, Canada, which encompassed a range of flow regimes and channel morphologies that are representative of a broad range of conditions that occur in mountain streams (Table 2.1; Figure 2.1; Figure 2.2). The study sites spanned a range of gradients between $0.17 \%$ and $9.48 \%$, stream discharges between $1 \mathrm{~m}^{3} \mathrm{~s}^{-1}$ and $400 \mathrm{~m}^{3} \mathrm{~s}^{-1}$, and suspended sediment concentrations from $5 \mathrm{mg} / \mathrm{L}$ to $700 \mathrm{mg} / \mathrm{L}$.

Sites with minimal topographic and vegetative shading were preferred in order to minimize shadows on the stream surface so that albedo measurements could be taken consistently in direct lighting conditions during clear weather. In order to sample a wide range of sun angles, suspended sediment concentrations and discharges, measurements were typically collected from mid-morning until sunset. Monitoring occurred on 29 days between May and September 2015 with the goal of sampling each site regularly throughout the field season. However, sampling during the field season was interrupted by wildfires in the region; access to upper Lillooet River and North Creek was prohibited during July and August as the result of the Cougar Creek wildfire in the Lillooet Valley. Heavy wildfire smoke throughout the area in early July created air quality concerns, preventing any sampling until smoke had dispersed. 


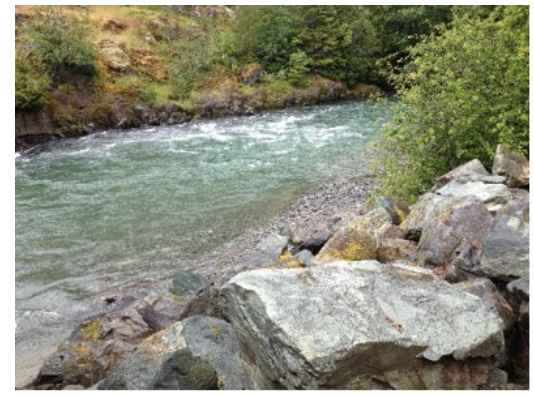

(a) Birkenhead River

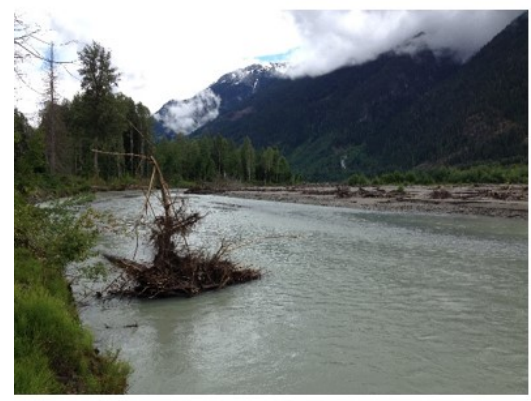

(d) Lillooet River at Lillooet FSR

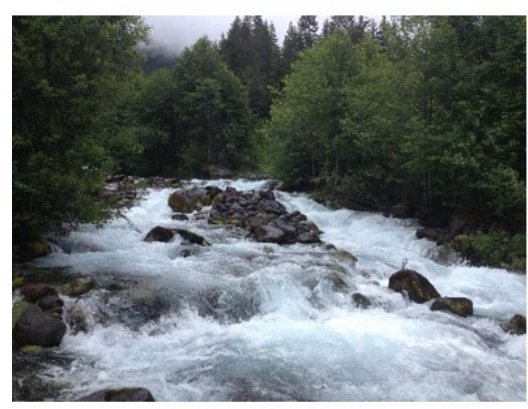

(g) Rubble Creek

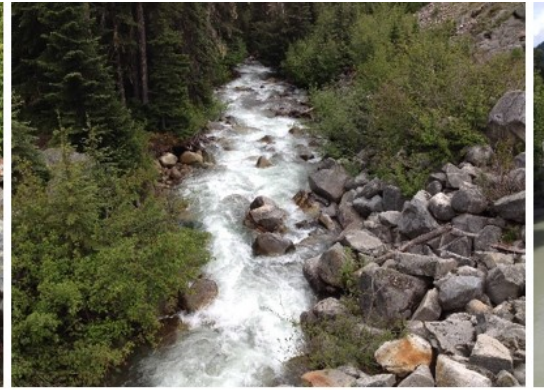

(b) Cayoosh Creek

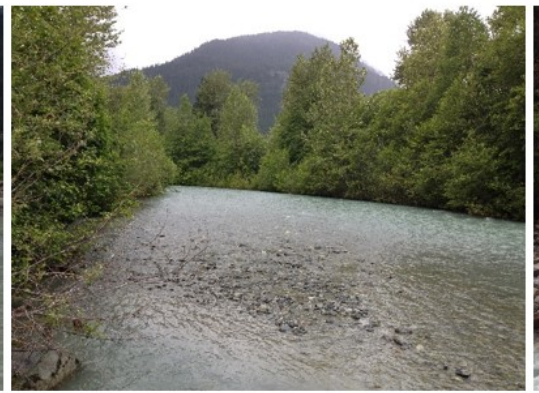

(e) Miller Creek

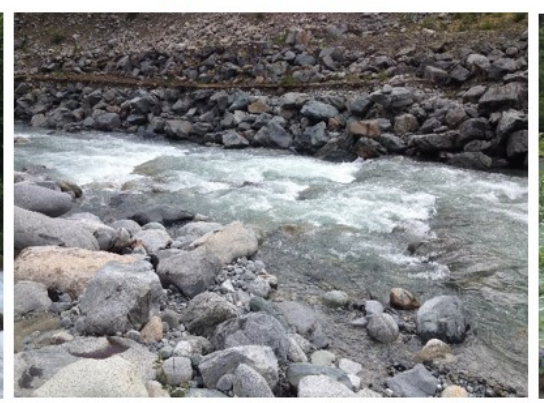

(h) Rutherford Creek

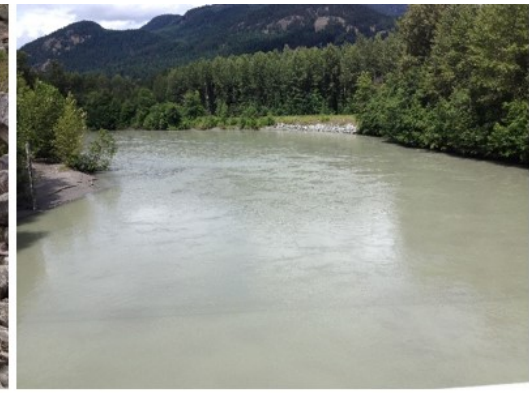

(c) Lillooet River at BC-99

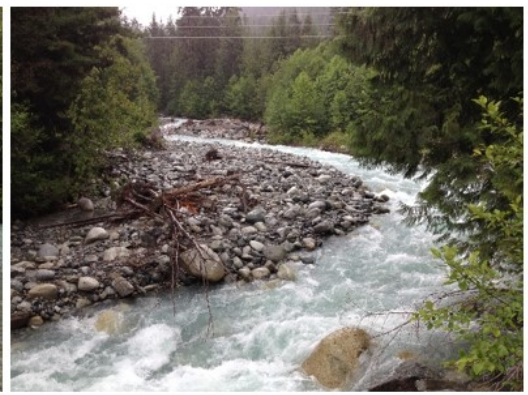

(f) North Creek

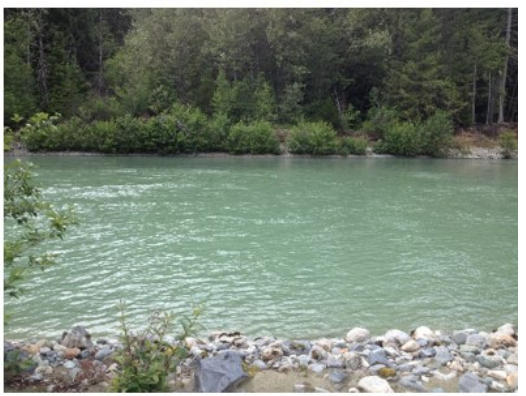

(i) Soo River

Figure 2.1: Sites used in the study. 


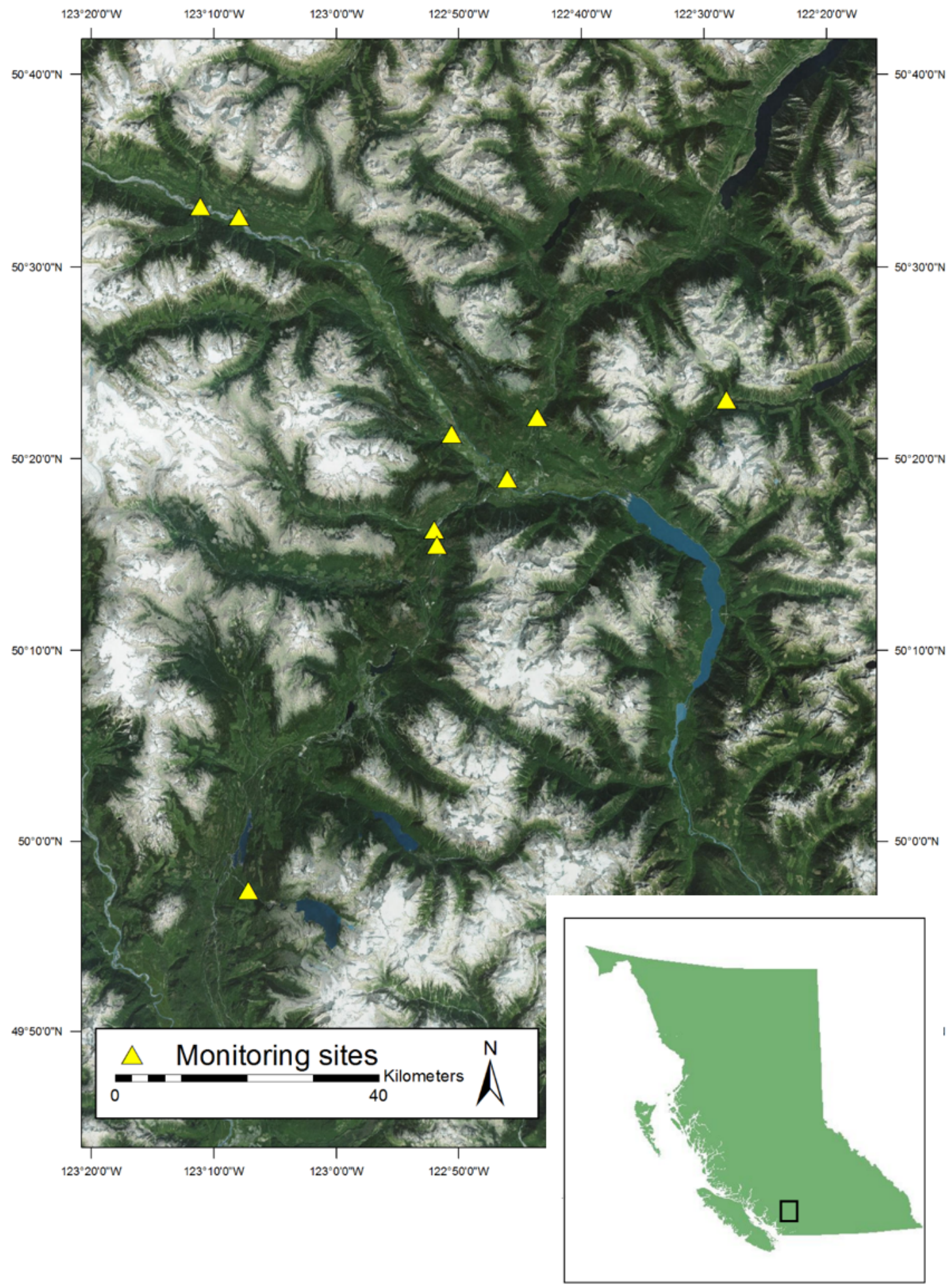

Figure 2.2: Map of the study area. 
Table 2.1: Stream reaches used in the study. No. Sites $=$ the number of sites on the reach where measurements were made. $V F=$ sky view factor.

* indicates that channel width was estimated from Google Earth. The lower Lillooet reach is located at the BC-99 road crossing. The upper reach is located at kilometre 15 on the North Lillooet Forest Service road.

\begin{tabular}{lcccllrl}
\hline Site & Latitude & Longitude & No. Sites & Channel Type & $\begin{array}{l}\text { Bankfull } \\
\text { Width }(\mathrm{m})\end{array}$ & Gradient (\%) & VF \\
& & & & & & \\
\hline Birkenhead R. & 50.370 & -122.727 & 2 & riffle-pool & 31.3 & 2.32 & 0.67 \\
Cayoosh Cr. & 50.385 & -122.469 & 2 & step-pool & 7.6 & 8.19 & 0.79 \\
Lillooet R. lower & 50.317 & -122.768 & 1 & riffle-pool & 68.4 & 0.58 & 0.76 \\
Lillooet R. upper & 50.542 & -123.129 & 1 & riffle-pool & $155^{*}$ & 0.24 & 0.63 \\
Miller Cr. & 50.356 & -122.843 & 1 & riffle-pool & 21.9 & 0.17 & 0.59 \\
North Cr. & 50.558 & -123.183 & 3 & cascade-pool & $10.5^{*}$ & 2.32 & 0.68 \\
Rubble Cr. & 49.957 & -122.120 & 3 & cascade-pool & 17.9 & 9.48 & 0.61 \\
Rutherford Cr. & 50.272 & -122.867 & 3 & cascade-pool & 37.7 & 5.81 & 0.90 \\
Soo R. & 50.258 & -122.864 & 1 & riffle-pool & 64.1 & 0.22 & 0.87 \\
\hline
\end{tabular}

\section{$2.2 \quad$ Field methods}

Incident and reflected solar radiation, $K \downarrow$ and $K \uparrow$, were measured with a pair of thermopile pyranometers mounted on a $2.5 \mathrm{~m}$ long pole suspended manually over the water surface and fixed to a tripod on shore (Figure 2.3). Incident solar radiation was measured with a Kipp \& Zonen CM6B pyranometer mounted facing upwards. An integrated level on the CM6B ensured that the pyranometer remained level during measurements. Reflected solar radiation was measured with a Kipp \& Zonen CM3 pyranometer pointed downwards and mounted to a gimbal joint to hold it level.

Pyranometers recorded voltage values $(\mathrm{mV})$ that were converted to irradiance $\left(\mathrm{Wm}^{-2}\right)$ using the sensitivity of each device $\left(\mathrm{mV} / \mathrm{Wm}^{-2}\right)$. The pyranometers were scanned every $1 \mathrm{~s}$ and averaged every $5 \mathrm{~s}$ with a Campbell Scientific CR10X data logger. Albedo, $\alpha$, was calculated as:

$$
\alpha=K \uparrow / K \downarrow
$$




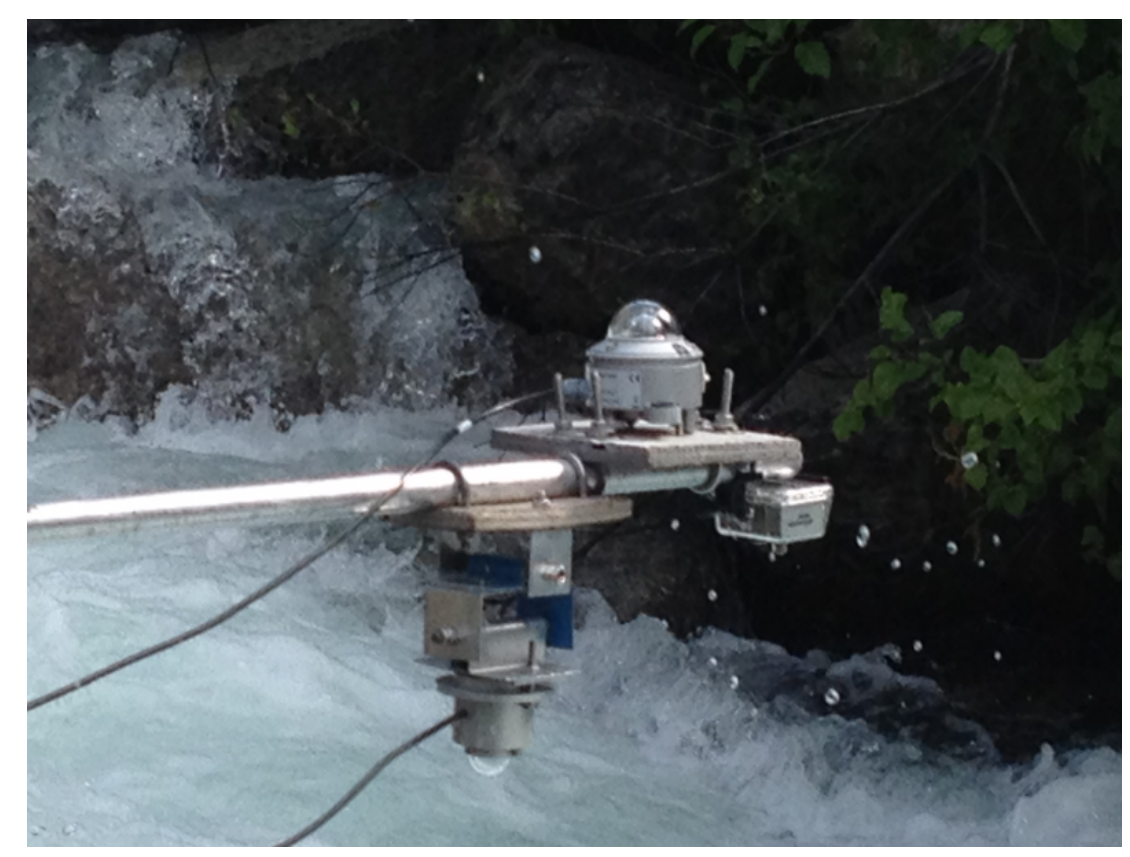

Figure 2.3: Monitoring set-up used to measure albedo and obtain camera imagery mounted at the end of the horizontal support pole.

Pyranometers were typically held at $0.5 \mathrm{~m}$ above the water surface during albedo measurements. Adjustments to height and orientation were made to keep shadows or rocks out of the pyranometer's field of view. When sampling at hydraulic jumps, pyranometers were positioned higher to prevent spray from swinging the lower pyranometer and compromising the stability of the measurement.

Albedo was sampled at several points on the stream surface at sites with visible whitewater to compare albedo values at points with varying degrees of aeration. During clear weather, each measurement usually lasted 60 to 120 s. Under variable lighting conditions, albedo values were not steady as incoming solar radiation values shifted, so measurements had to be longer to ensure that a steady albedo value had been obtained. Pyranometers were covered between measurements to zero out irradiance values and protect the instrumentation. During clear weather with consistent lighting conditions, albedo measurements were taken every $30 \mathrm{~min}$. Additional measurements were taken during periods of variable cloud cover when atmospheric transmissivity changed frequently. Reflected irradiance was measured during rainy weather early in the study period, but values were small enough that they were difficult to distinguish from noise and resulting albedo values were unreliable. Therefore, sampling was avoided during periods of rain, when incoming solar radiation was minimal. 


\subsubsection{Suspended sediment}

Suspended sediment samples were collected every $2 \mathrm{~h}$ using a DH-48 depth-integrated sampler at the location of each albedo measurement. Samples were processed at a laboratory at the UBC Department of Geography. The mass of sediment in each sample was calculated by weighing 47 -mm glass microfiber filters, pumping samples through the filters, and then drying and re-weighing each filter. Suspended sediment concentration, $S S C(\mathrm{mg} / \mathrm{L})$, was then calculated by dividing the sediment mass by the sample volume.

\subsubsection{Streamflow}

Discharge was measured at reaches in which albedo measurements were made over aerated portions of streamflow. Channels where streamflow measurements were recorded tended to be narrow, relatively steep, irregular, and boulder filled with cascade-pool or step-pool morphologies, and were appropriate for salt dilution gauging in place of the standard velocity-area method. Dry salt injection was used since flow was adequately turbulent to facilitate rapid solute dissolution and mixing (Hudson and Fraser, 2005; Richardson, 2015). Salt was injected hourly or more frequently if stream discharge changed rapidly. Temperature-corrected electrical conductivity, $E C_{T}$, was monitored with a pair of WTW Cond 3310 conductivity meters and WTW Tetracon conductivity probes downstream of the injection point. The meters were staggered by 5 to $10 \mathrm{~m}$ in order to verify that complete solute mixing had occurred. Background $E C_{T}\left(E C_{B G}\right)$ was measured prior to injection, and the changes in $E C_{T}$ were monitored as the injected salt wave moved past the probes until $E C_{T}$ had returned to the background level. The temperaturecorrected calibration factor $C F_{T}\left(\mathrm{~kg} \mathrm{~m}^{-3} /\left(\mu \mathrm{S} \cdot \mathrm{cm}^{-1}\right)\right.$ was calculated at the end of each monitoring day using the procedure described by Richardson (2015), in which a known mass of salt was added to a measured volume of streamwater, and then samples of this solution were added incrementally to another measured volume of streamwater, with $E C_{T}$ measured after each addition. $C F_{T}$ was calculated as the slope of the linear regression line between the calculated mass concentration of salt and $E C_{T}$. Following calibration, stream discharge, $\mathrm{Q}\left(\mathrm{m}^{3} \mathrm{~s}^{-1}\right)$, was calculated as:

$$
Q=\frac{M}{C F_{T} \cdot A}
$$

where $M$ is the mass of the salt injected $(\mathrm{kg})$, and $A$ is the area under the time series of $\left(E C_{T}-E C_{B G}\right)$ during the salt wave passage $\left(\mu \mathrm{S} \cdot \mathrm{cm}^{-1} \cdot \mathrm{s}\right)$. 


\subsubsection{Digital camera imagery}

Video of the water surface was recorded during each albedo measurement using a waterproof GoPro HDHERO2 digital camera. The camera was mounted facing downwards on the pole mount and was run continuously for the duration of each measurement (Figure 2.3). Video collected was used to provide imagery to refer to while processing and verifying albedo data as well as for the development of a proxy for pyranometer-measured albedo.

\subsubsection{Reach characteristics}

Surveys were conducted in June and August 2016 to determine the view factor, average bankfull channel width, and channel gradient of each site using a LTI Impulse 200 laser rangefinder and handheld clinometer. Average bankfull width was calculated as the average width of two transects of each stream and was obtained with horizontal rangefinder measurements. Gradient was determined by obtaining horizontal and vertical distance measurements with the rangefinder. The sky view factor $(V F)$ was calculated from zenith angles measured at each site in eight directions (N, NE, E, etc.):

$$
V F=\frac{\sum_{i=1}^{8}\left[1-(\cos Z)^{2}\right]}{8}
$$

where $Z$ is the angle between the zenith and the horizon (defined by topography or forest canopy) in each direction, measured with a clinometer.

\subsection{Data analysis}

\subsubsection{Pyranometer calibration}

Using the manufacturer's calibration sensitivities for each pyranometer, irradiance values from the CM3 pyranometer were typically 91 to $95 \%$ of the values recorded by the CM6B. There was no offset between pyranometers when both were covered and zeroed. This proportional offset was compensated for by calibrating the voltages reported by the CM3 pyranometer with those reported by the CM6B. At the conclusion of each trip to the field, pyranometers were run side by side for several hours. A linear model with no intercept was fitted between the CM3 raw voltage output and the CM6B irradiance. The recorded CM3 voltage was then multiplied by the model's slope to calculate the calibrated CM3 irradiance. 


\subsubsection{Albedo calculation}

Following pyranometer calibration, albedo values were extracted from the pyranometer time series. A five-point moving window, corresponding to 25 seconds of measurement time, was used to calculate smoothed means and standard deviations of $K \downarrow$, time of measurement, and albedo (Figure 2.4). Stable measurements were isolated by removing periods between measurements, unstable measurements, and the leading and trailing edge of each measurement by removing points where $K \downarrow$ within each window exceeded a set standard deviation and slope. Albedo, measurement time, and $K \downarrow$ were calculated as the mean of the values for each measurement period. Further manual processing was performed in order to determine whether measured albedo values were physically reasonable by comparing them to field notes and the digital camera imagery. Unstable albedo measurements that were not removed by the filter were also discarded from the dataset. Lighting conditions and an estimate of the amount of surface aeration for each albedo measurement (i.e. minimal aeration versus highly aerated) were appended to the dataset from field notes.

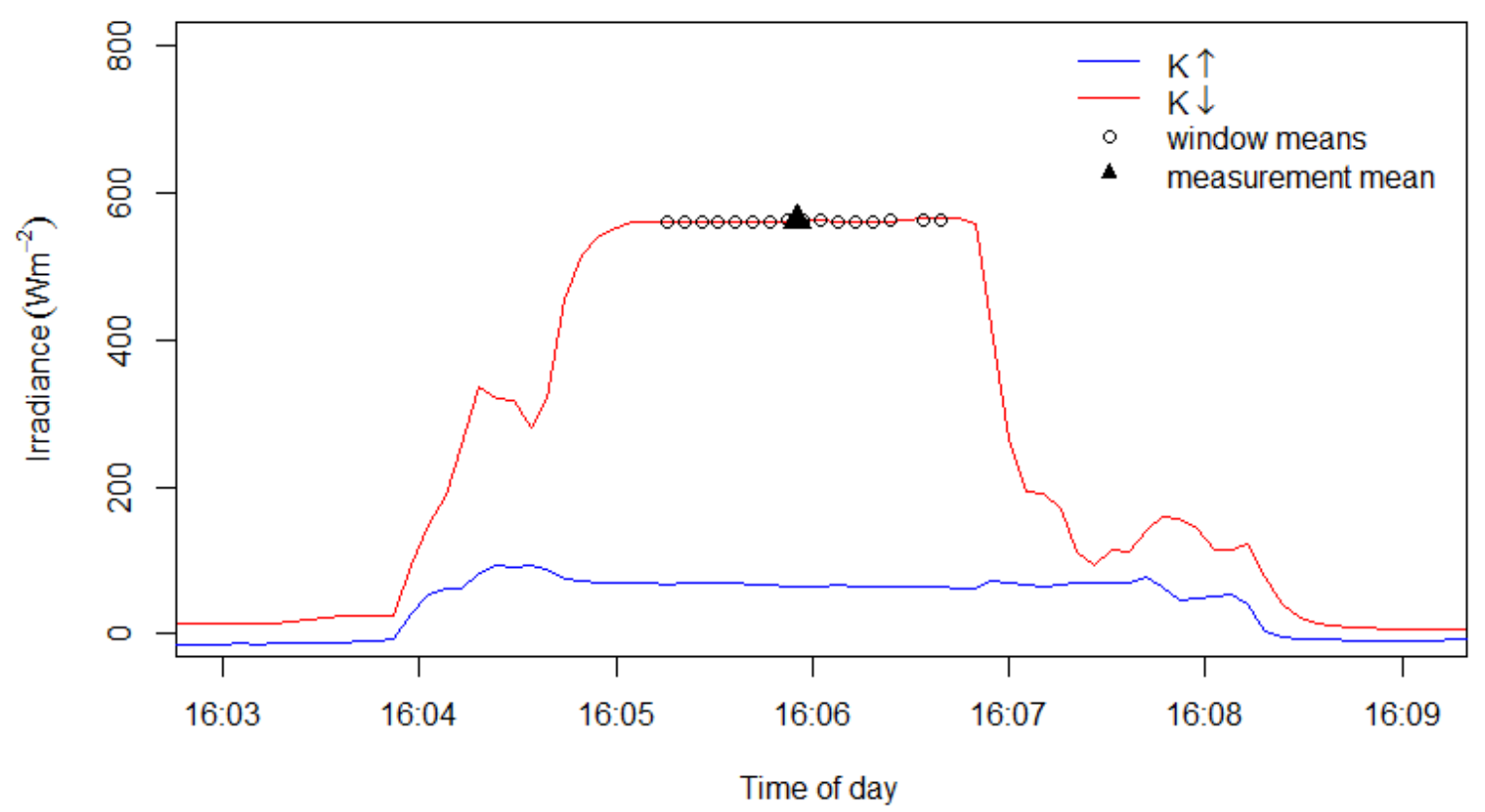

Figure 2.4: Sample albedo time series measurement. Hollow circles are centroids of each 5-point window within the measurement. The black triangle denotes the position of the mean $K \downarrow$ within the measurement. 


\subsubsection{Solar position}

Albedo should vary with solar zenith angle (which, for a horizontal water surface, is also the angle of incidence) and with the fractions of direct and diffuse solar radiation. For simplicity, the atmospheric transmissivity, $\tau$, was used as an index of these fractions (i.e., higher transmissivity indicates a higher fraction of direct radiation). Solar zenith angle, $\theta$, was calculated following Iqbal (1983):

$$
\theta=\cos ^{-1}[\sin (\delta) \cdot \sin (\phi)+\cos (\delta) \cdot \cos (\omega)]
$$

where $\delta$ is solar declination, $\phi$ is latitude at the measurement location, and $\omega$ is the hour angle. The declination was calculated based on a seven term Fourier expansion:

$$
\begin{aligned}
\delta=0.0069- & 0.3999 \cos (\gamma)+0.0703 \sin (\gamma) \\
& -0.0068 \cos (2 \gamma)+0.0009 \sin (2 \gamma)-0.0027 \cos (3 \gamma)+0.0015 \sin (3 \gamma)
\end{aligned}
$$

where $\gamma$ is the day angle, $2 \pi(d-1) / 365$, where $d$ is the calendar day $(d=1$ on Jan. 1$)$. Hour angle was calculated as:

$$
\omega=0.2618\left(L_{t}-12\right)
$$

where $L_{t}$ is local area time, calculated as:

$$
L_{t}=T_{d}-D S T+4\left(\lambda_{\text {standard }}-\lambda\right) / 60+E_{t}
$$

where $\lambda$ is longitude, $T_{d}$ is the local clock time, $\lambda_{\text {standard }}$ is a standard parallel of longitude $\left(120^{\circ} \mathrm{W}\right.$ for the region), and $E_{t}$ is the equation of time, calculated with a five term Fourier expansion:

$$
\begin{aligned}
E_{t}=229.18[0.000075 & +0.001868 \cos (\gamma) \\
& -0.032077 \sin (\gamma)-0.014615 \cos (2 \gamma)-0.04089 \sin (2 \gamma)] / 60
\end{aligned}
$$

Transmissivity was calculated as:

$$
\tau=K \downarrow /\left[K_{0} \cos (i)\right]
$$

where $K_{0}$ is the solar constant, taken here to be $1367 \mathrm{Wm}^{-1}$, and $i$ is the solar incidence 
angle, approximated here by the solar zenith angle. To simplify interpretation, further analysis was performed using the solar elevation angle, $h$, which is the complement of solar zenith angle.

\subsubsection{Digital camera imagery}

Still frames from the digital camera imagery were used to develop a proxy measure for aeration. Still frames were extracted from the digital camera video recorded between June and September at Rutherford Creek. One video frame was extracted per albedo measurement taken at each site. Each frame was converted into a 3-dimensional matrix representing the image's red, green, and blue components, where the number of columns and rows in each matrix channel was equal to the image's height and width in pixels. The coefficient of variation $(C V)$ of the pixels in each colour channel was calculated and averaged between all three colours as a measure of the total variability within the image. Nonlinear regression was used to fit a model relating albedo to $C V$ to assess its value as a proxy.

\subsubsection{Statistical modelling}

Albedo measurements were stratified into a "whitewater" set for measurements that took place over visibly aerated flow and a separate "flatwater" subset for the rest. A separate subset was created for measurements taking place at a hydraulic jump on Rutherford Creek to look explicitly into the relation between albedo and discharge. Discharge measurements were also made on Cayoosh Creek and North Creek, but neither stream had an adequate number of discharge measurements associated with albedo at a specific location on the stream to perform a valid statistical analysis. Since albedo measurements were not always taken at the same time as discharge and suspended sediment, $Q$ and $S S C$ values were assigned to each albedo measurement using cubic spline interpolation through the time series of those variables for each day. Splines were generated according to Forsythe et al. (1977); in this approach end conditions were determined by fitting an exact cubic through the four points on each end of the data, thus minimizing the spline energy subject to constraints imposed by the end conditions

Albedo was plotted individually against solar elevation angle, transmissivity, suspended sediment concentration, and discharge to determine the forms of the relation. Predictors were transformed if, during the initial stages of model fitting, it appeared necessary to linearize the relationship and to improve predictive ability. A categorical representation of $S S C$ was used in which low concentrations were assigned a value of 0 , 
and higher concentrations were assigned a value of 1 . The split between low and high concentrations was defined at $30 \mathrm{mg} / \mathrm{L}$ for the flatwater subset and at $15 \mathrm{mg} / \mathrm{L}$ for the whitewater subset. Additionally, $\sin h$ was used in order to linearize the relationship between solar altitude and albedo. Transformed variables were used to fit models for albedo using multiple regression separately for the flatwater and whitewater subsets. A set of candidate models was constructed for every possible combination of selected variables and their interactions.

Candidate models were initially evaluated on the basis of coefficient values. Models with coefficients that were not physically reasonable were immediately removed from consideration. The predictive ability of remaining models was compared with the Akaike Information Criterion $(A I C)$ for the model fitted to the entire subset. A modified version of the metric, $A I C_{c}$, was used, since the number of observations was relatively small compared to the number of predictor variables, and since $A I C_{c}$ imposes a greater penalty for extra predictors (Symonds and Moussalli, 2011). Candidate models with $\triangle A I C_{c}$ of less than 2 for each subset were evaluated further using leave-one-out cross validation. Models were cross-validated on a stream-by-stream basis to avoid overfitting and to produce a more rigorous test of the model's predictive ability when applied to new sites.

Recursive partitioning was used to categorize variability in the dataset and identify interactions between predictor variables. The resultant regression trees classified subsets of the albedo dataset based on how predictor variables reduced variance in each subset of albedo. Regression trees were pruned using a complexity parameter $\left(c_{p}\right)$ of 0.04 . Results of recursive partitioning were used to draw inferences regarding the relative importance of each predictor variable and the structure of the relationship between albedo and predictors. 


\section{Chapter 3}

\section{Results}

\subsection{Overview of the study period}

Monthly mean air temperatures measured near Pemberton, BC, from 1969-2014 and during 2015 are displayed in Figure 3.1. The majority of the study period was characterized by air temperatures well above monthly averages. The mean monthly air temperature was $3.7^{\circ} \mathrm{C}$ above normal during May and June and $2.4{ }^{\circ} \mathrm{C}$ above average in July. Temperatures toward the end of the field season were closer to long-term averages. The mean monthly air temperature was $1.0{ }^{\circ} \mathrm{C}$ above average in August and $0.4{ }^{\circ} \mathrm{C}$ below average in September.

Historical monthly mean total precipitation from 1969-2014 and 2015 monthly total precipitation are displayed in Figure 3.2. Monthly precipitation was below the long term average during much of the spring of 2015 and for the majority of the field season. Less than half of average precipitation fell during April, May, and July 2015. May 2015 was particularly dry; $9.6 \%$ of monthly average precipitation occurred. In contrast, August and September 2015 were wet months, receiving $263 \%$ and 176\% of average total monthly precipitation respectively. 


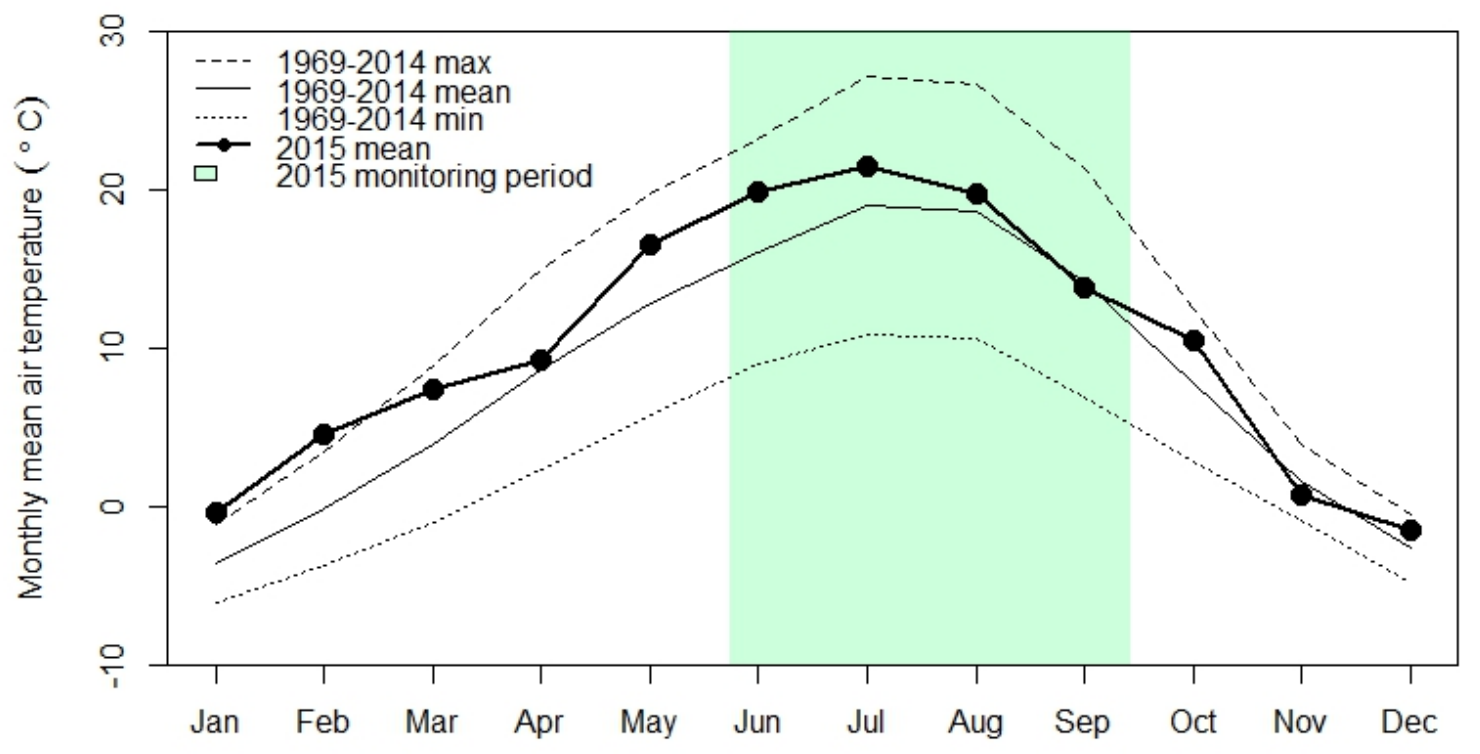

Figure 3.1: Historical maximum, mean, and minimum monthly air temperatures and 2015 monthly mean air temperature measured near Pemberton. The 2015 field season is highlighted in blue. Data from 1969 - 1984 are sourced from Environment Canada station 1086083 (Pemberton BCFS), with years 1984 - 2015 sourced from a nearby station, 1086082 (Pemberton Airport CS). 


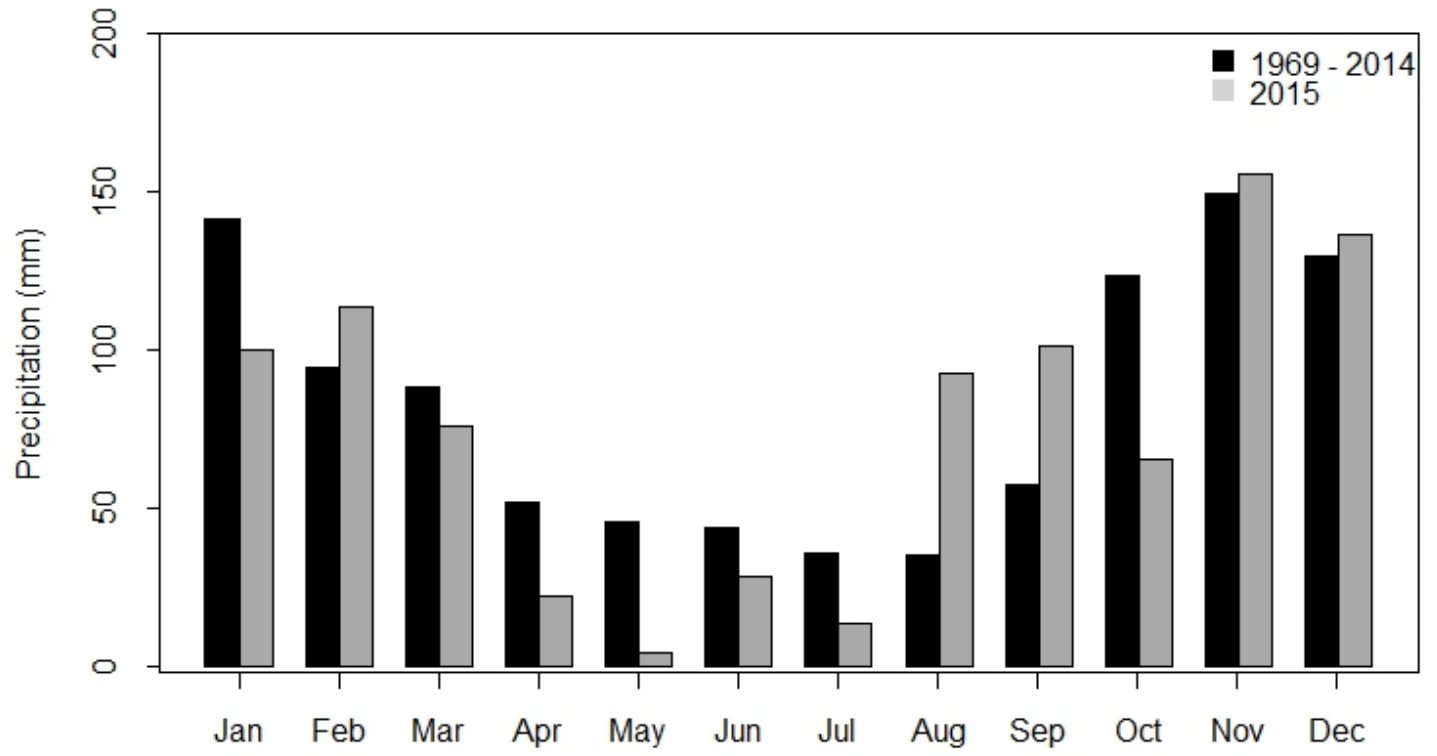

Figure 3.2: Historical mean monthly total precipitation and 2015 monthly total precipitation measured near Pemberton. Data from 19691984 are sourced from Environment Canada station 1086083 (Pemberton BCFS), with years 1984 - 2015 sourced from station 1086082 (Pemberton Airport CS). 
Peak summer flow on the Lillooet River occurred during the beginning of the 2015 field season (Figure 3.3). Peak summer flows occurred during late May and early June, well before the mid-July average. The early peak is likely attributable to meltwater generation resulting from higher than average air temperatures during the late spring and early summer. Rainfall was below average during the same period, minimizing precipitation contributions to streamflow. Daily mean streamflow was above average for much of July, and returned to near-normal conditions in late July and August as more precipitation fell and temperatures returned to long-term averages.

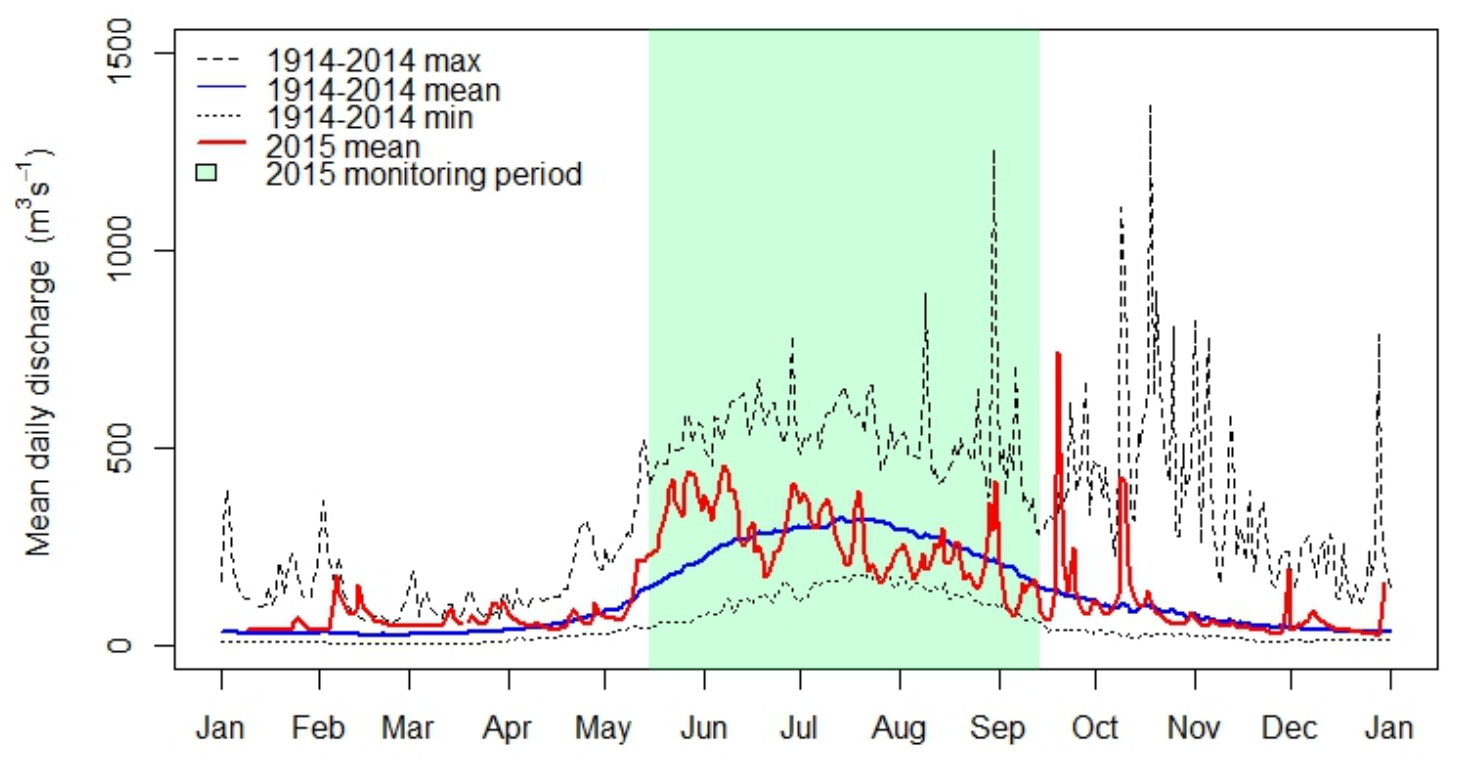

Figure 3.3: Historical maximum, mean, and minimum daily streamflow and 2015 mean flow at the Lillooet River $3 \mathrm{~km}$ northwest of the Lower Lillooet reach (Water Survey of Canada station 08MG005 Lillooet River near Pemberton)

\subsection{Pyranometer calibration}

The relation between CM6B irradiance and CM3 output voltage used to calculate CM3 irradiance is shown in Figure 3.4. Prior to calibration, percent difference between daily CM3 and CM6B irradiance during parallel runs differed from between $4.7 \%$ and $18.7 \%$. Following calibration, percent difference between pyranometers was $0.7 \%$ to $14.0 \%$ (Table 3.4). Standard error of the estimate was between 4.3 and $18.7 \mathrm{Wm}^{-2}$. The largest differences in irradiance following calibration occurred on days when shading from clouds 
or buildings covered pyranometers during the calibration procedure, creating periods in which one pyranometer would be shaded while the other was exposed to direct solar radiation. On July 21 and August 3, shadows from nearby buildings covered the pyranometers after several hours of recording in direct solar radiation.

Table 3.1: Pyranometer calibration results. Percent differences are between CM3 and CM6B irradiance. $\mathrm{S}_{e}=$ standard error of the estimate.

\begin{tabular}{lccc}
\hline calibration date & \% difference calibrated & slope $\left(\mathrm{Wm}^{-2} / \mathrm{mV}\right)$ & $\mathrm{S}_{e}\left(\mathrm{Wm}^{-2}\right)$ \\
\hline 31 May & -0.67 & 55.32 & 7.2 \\
18 June & -0.94 & 56.75 & 4.25 \\
21 July & -4.33 & 57.2 & 9.73 \\
3 August & -14.0 & 56.15 & 13.91 \\
24 August & -1.09 & 56.07 & 12.73 \\
21 September & -5.6 & 56.48 & 18.66 \\
\hline
\end{tabular}

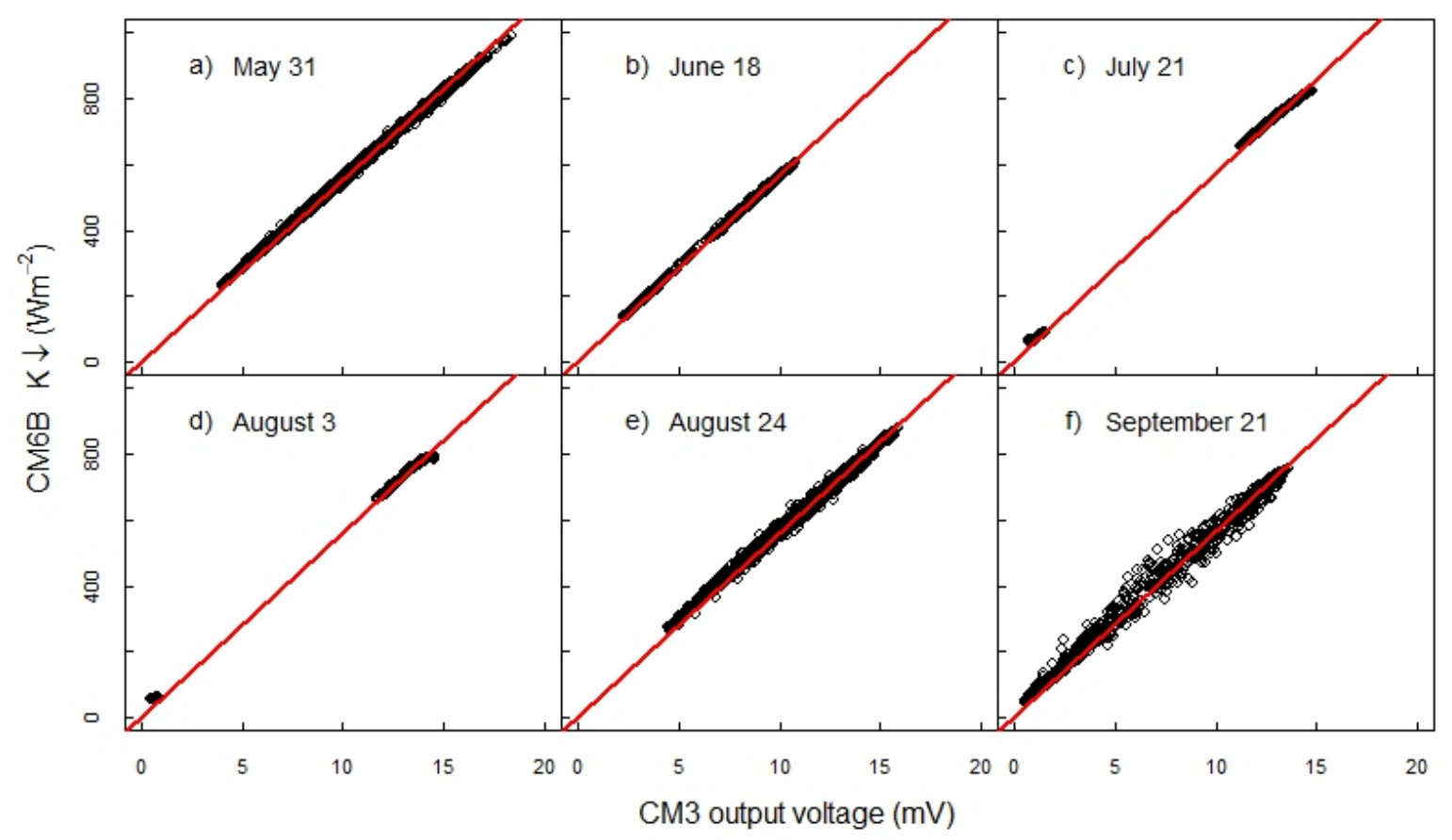

Figure 3.4: Relation between uncalibrated CM3 output voltage and CM6B irradiance during calibration. Red lines are the regression lines for each relation used to convert the CM3 voltage to irradiance

The period of time in which the pyranometers were not exposed to identical light conditions was removed, producing the discontinuities in panels 3.4c and $3.4 \mathrm{~d}$ (Figure 3.4). Percent difference following calibration was $4.3 \%$ on July 21 and $14.0 \%$ on August 
3. Calibration on September 21 occurred during a period of variable clouds that induced scatter in the relation as shadows moved over the pyranometers, again subjecting them to non-identical irradiances (Figure 3.4f). On days when shading was minimal, calibrated CM3 and CM6B irradiance differed by $1.1 \%$ or less.

Variability in the slope of the regression line was minimal despite differences in light conditions during calibration and relatively large differences in calibrated values on $\mathrm{Au}-$ gust 3 and September 21. Regression slopes ranged between 55.3 and $57.2 \mathrm{Wm}^{-2} / \mathrm{mV}$. The percent difference between the maximum and minimum vales was $3.3 \%$. Additionally, no trend in the slope of the regression was evident over the course of the monitoring season, indicating that the calibration process produced consistent calibrated irradiance values and that any systematic drift was minimal.

\subsection{Analysis of digital camera images}

Digital images were captured at Rutherford Creek during trips to the site between June and September at three locations along the stream surface that encompassed a gradient of visible aeration (Figure 3.5, panels a - c). Measurements at location (a) were made over slow moving flow upstream of a rock step. Measurements at (b) and (c) were downstream of the rock step, where (c) was immediately in the lee of the boulder over layers of foam on the water surface, and b) was approximately $2 \mathrm{~m}$ downstream.

Linear regressions fitted between albedo and CV for each subset were not significant. Plotted together, the albedo-CV relation appears consistent with a logistic curve, although with considerable scatter. Model residuals had a standard deviation of 0.041 and Nash-Sutcliffe efficiency of 0.28 . 

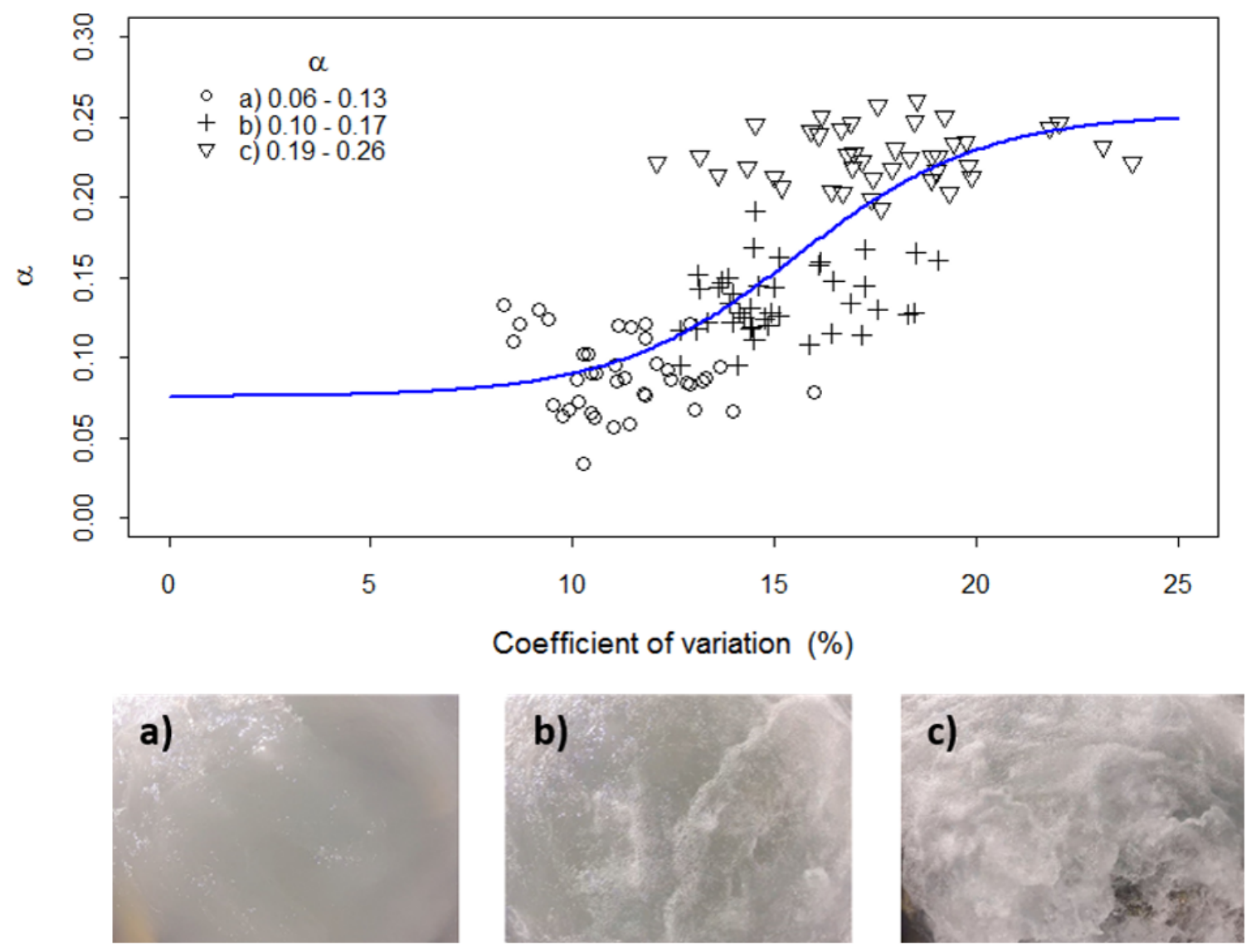

Figure 3.5: Upper panel shows the relation between measured albedo and the coefficient of variation of pixel RGB values at Rutherford Creek based on measurements at three locations denoted $\mathrm{a}, \mathrm{b}$ and $\mathrm{c}$. The lower panels provide an example image for each site.

\subsection{Exploratory analysis of albedo variability}

In this section, the relation between albedo and several hypothesized controlling variables (atmospheric emissivity, solar elevation angle, suspended sediment concentration and discharge) are examined. Sections 3.4.1 to 3.4.4, below, present exploratory analyses using bivariate graphs with stratification, and section 3.4.5 examines the potentially interacting effect of all candidate predictor variables using recursive partitioning. The results of these exploratory analyses are then used to define the form of a formal predictive model in section 3.5 . 


\subsubsection{Relation with atmospheric transmissivity}

The relation between albedo and atmospheric transmissivity is displayed in Figure 3.6. Albedo exhibited a slight positive correlation with transmissivity for both subsets. A shift in the mean and variance of albedo is apparent at around $\tau=0.6$. Mean albedo was decreased by 0.03 within the flatwater subset and 0.02 within the whitewater subset when $\tau<0.6$. Standard deviation from the mean within each subset decreased 0.006 for flatwater and 0.009 for whitewater over the range of measurements.

Compared to a subjective classification of the dominant insolation condition (direct vs diffuse), defining diffuse as dominant for $\tau<0.6$ and direct for $\tau \geq 0.6$ matched observed lighting conditions for $97 \%$ of albedo measurements. Since sampling typically took place during fair weather, the majority of albedo measurements were taken in direct lighting conditions in both subsets. A total of 66 of 212 flatwater measurements and 17 of 91 whitewater measurements were measured when $\tau>0.6$.

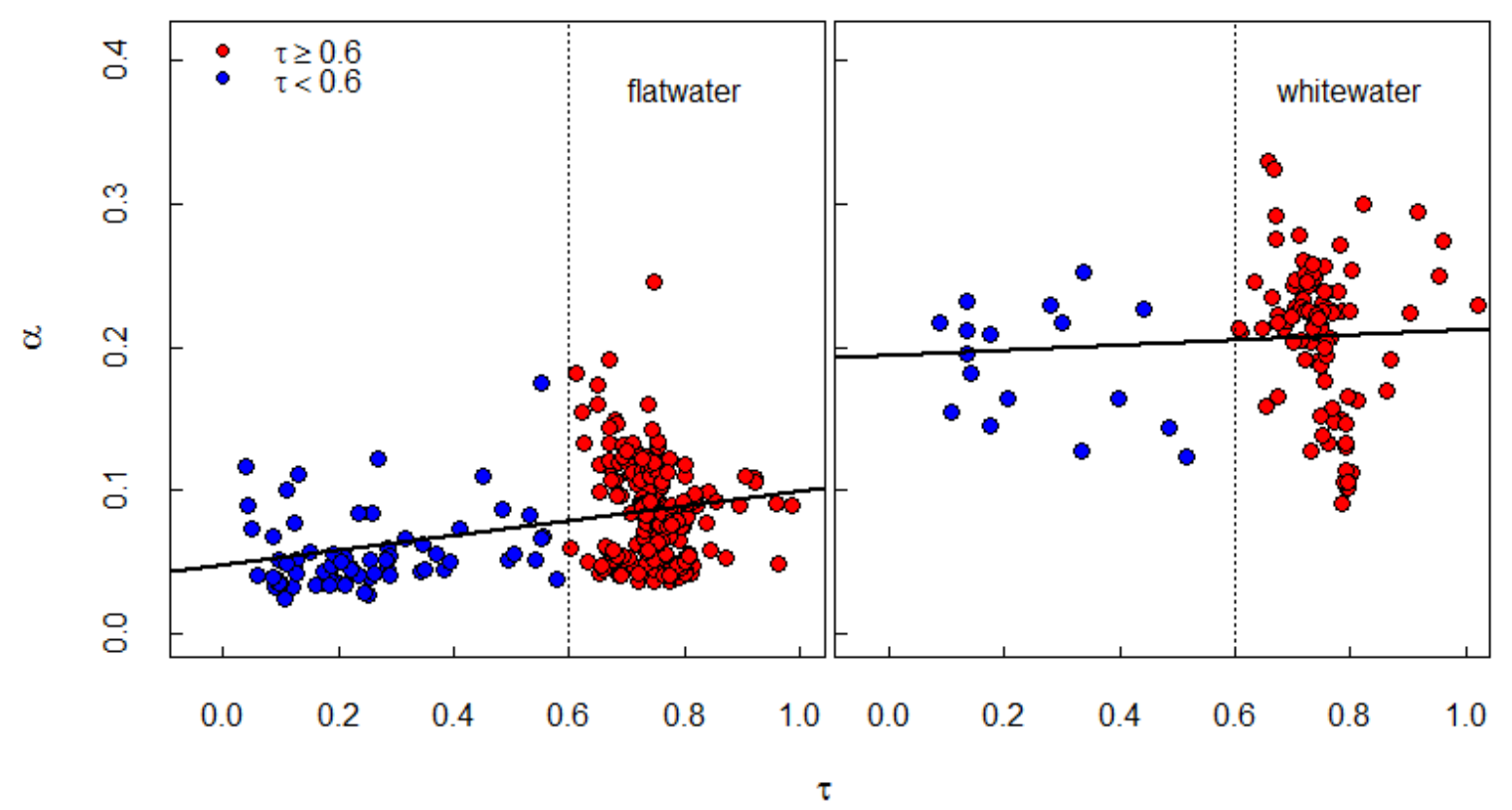

Figure 3.6: Albedo as a function of atmospheric transmissivity for flatwater (left panel) and whitewater (right panel) sites. Solid black lines are regression lines for each subset. Vertical dotted lines at $\tau=0.6$ indicate an inferred split between light conditions dominated by diffuse $(\tau<0.6)$ and direct insolation $(\tau \geq 0.6)$, respectively. 


\subsubsection{Relation with solar elevation angle}

Stream surface albedo exhibited a broad range of variability associated with solar elevation angle (Table 3.2; Figure 3.7). Flatwater measurements ranged from 0.036 to 0.246 in direct light conditions, with a mean of 0.057 . Albedo was enhanced by aeration at points on the stream with visible whitewater, and more scatter was present in the relation. Albedo ranged from 0.09 to 0.329 in direct light, with a mean of 0.189. Albedo exhibited a negative response with solar elevation angle in direct light, particularly for elevation angles below $25^{\circ}$ during flatwater measurements. Albedo decreased within both subsets during diffuse lighting conditions when the response to solar elevation was suppressed. Differences in albedo during direct and diffuse lighting conditions were most pronounced at low solar elevation angles.

Flatwater albedo in diffuse light ranged from 0.025 to 0.175 in flatwater and from 0.124 to 0.188 in whitewater. The slopes of the relation between albedo and solar elevation were significant for all subsets other than whitewater albedo measurements in diffuse light, which consists of 17 measurements. Measurements over whitewater exhibited more scatter than flatwater measurements. More scatter was inherent in the relation for direct lighting conditions compared to diffuse lighting conditions within both subsets, as evidenced by higher standard deviations.

Table 3.2: Summary of albedo values for flatwater and whitewater subsets and relations with solar elevation angle, stratified by transmissivity. Slope refers to the slope of the relation between albedo and solar elevation angle, $n$ is the number of points in each subset, and $p$ is the significance level for the regression.

\begin{tabular}{lllcccccc}
\hline & $\tau$ & Min & Mean & Max & Std. Dev. & Slope & $p$ & $n$ \\
\hline \multirow{2}{*}{ Flatwater } & $\geq 0.6$ & 0.036 & 0.088 & 0.246 & 0.033 & -0.002 & $2 \mathrm{e}-16$ & 212 \\
& $<0.6$ & 0.025 & 0.057 & 0.175 & 0.027 & -0.0009 & 0.0003 & 66 \\
\multirow{3}{*}{ Whitewater } & $\geq 0.6$ & 0.091 & 0.210 & 0.329 & 0.049 & -0.003 & $1.07 \mathrm{e}-9$ & 98 \\
& $<0.6$ & 0.124 & 0.188 & 0.253 & 0.040 & -0.0003 & 0.645 & 17 \\
\hline
\end{tabular}




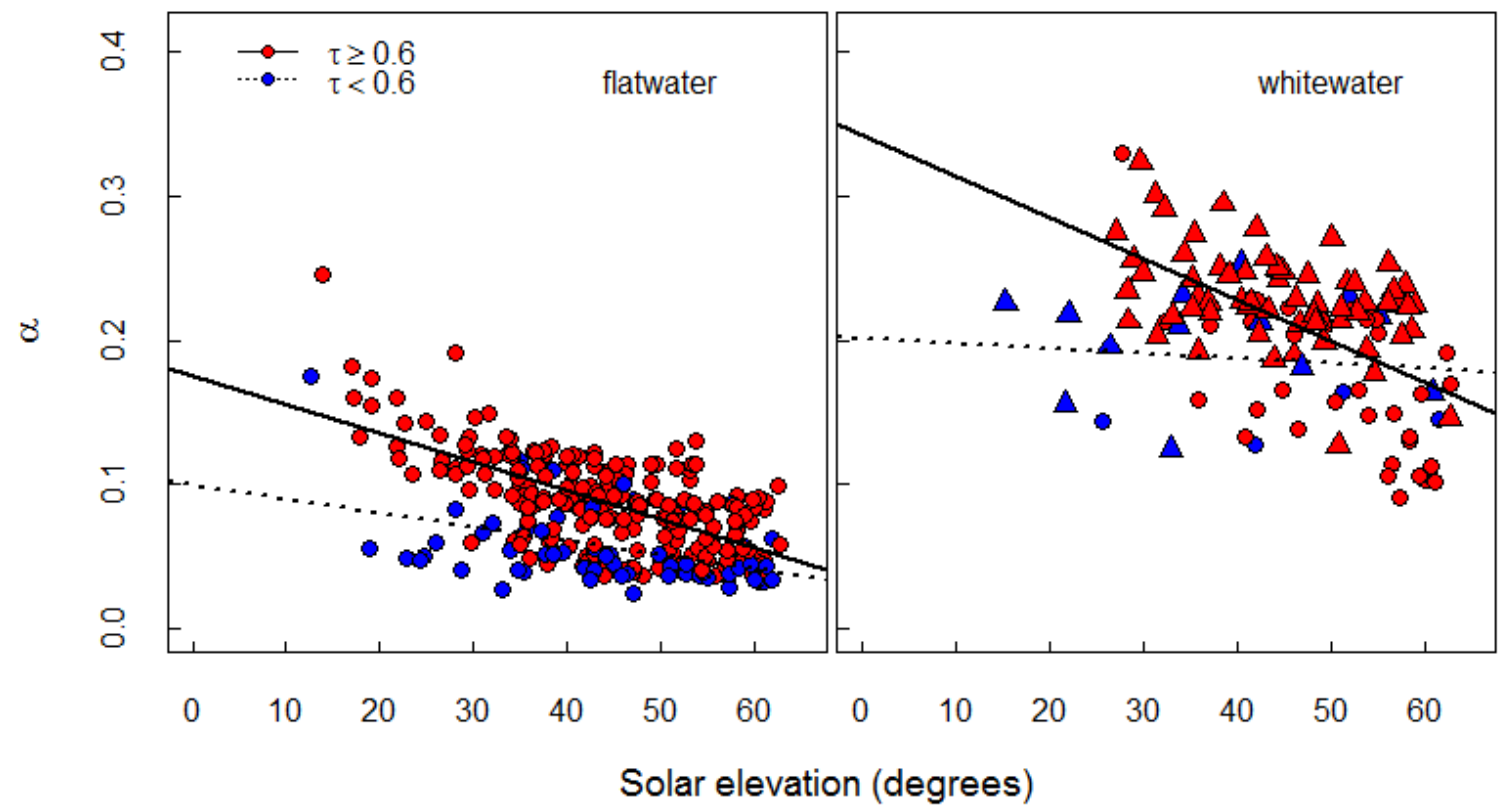

Figure 3.7: Albedo as a function of solar elevation angle. Solid and dashed lines are best-fit regressions for direct- and diffuse-dominated conditions, respectively.

\subsubsection{Relation with suspended sediment}

Suspended sediment concentrations and associated flatwater albedo and transmissivity values for each reach are listed in Table 3.3. Minimum and maximum concentrations measured during the field season were $0.83 \mathrm{mg} / \mathrm{L}$, measured at Cayoosh Creek, and $746 \mathrm{mg} / \mathrm{L}$, measured on the Lower Lillooet River. The sites had mean albedo values of 0.05 and 0.10 respectively. The albedo- $S S C$ relation is shown on log-axes for the complete flatwater and whitewater subsets in Figure 3.8. The relation is plotted with linear x-axes in Figure 3.9. Albedo had a strong positive relation with $S S C$ at low concentrations that flattened at higher concentrations. Transmissivity had a weak influence on the relation for the flatwater subset. The slope of the relation for flatwater was 0.026 for measurements in direct light, compared to 0.020 for diffuse conditions. The difference was greater for the whitewater measurements. Slopes of the regression were 0.047 and 0.026 for direct and diffuse conditions respectively. However, the slope of the regression was not significant for diffuse measurements in either the flatwater or the whitewater subset. 
Table 3.3: Minumum, mean, and maximum $S S C$ values, mean flatwater albedo, and mean transmissivity observed for each reach. Albedo measurements over aerated flow were excluded from the calculation of mean albedo.

\begin{tabular}{lccccc}
\hline Reach & $\begin{array}{c}\min S S C \\
(\mathrm{mg} / \mathrm{L})\end{array}$ & $\begin{array}{c}\operatorname{mean} S S C \\
(\mathrm{mg} / \mathrm{L})\end{array}$ & $\begin{array}{c}\max S S C \\
(\mathrm{mg} / \mathrm{L})\end{array}$ & mean $\alpha$ & mean $\tau$ \\
\hline Birkenhead R. & 2.37 & 15.1 & 182 & 0.050 & 0.491 \\
Cayoosh Cr. & 0.83 & 2.50 & 7.23 & 0.054 & 0.727 \\
Lillooet R. lower & 173 & 405 & 747 & 0.099 & 0.713 \\
Lillooet R upper & 208 & 375 & 677 & 0.114 & 0.710 \\
Miller Cr. & 13.1 & 26.2 & 41.7 & 0.047 & 0.335 \\
North Cr. & 24.9 & 35.4 & 43.2 & 0.062 & 0.611 \\
Rubble Cr. & 1.63 & 117 & 650 & 0.087 & 0.628 \\
Rutherford Cr. & 3.25 & 22.8 & 40.1 & 0.088 & 0.693 \\
Soo R. & 15.7 & 75.5 & 166 & 0.105 & 0.692 \\
\hline
\end{tabular}

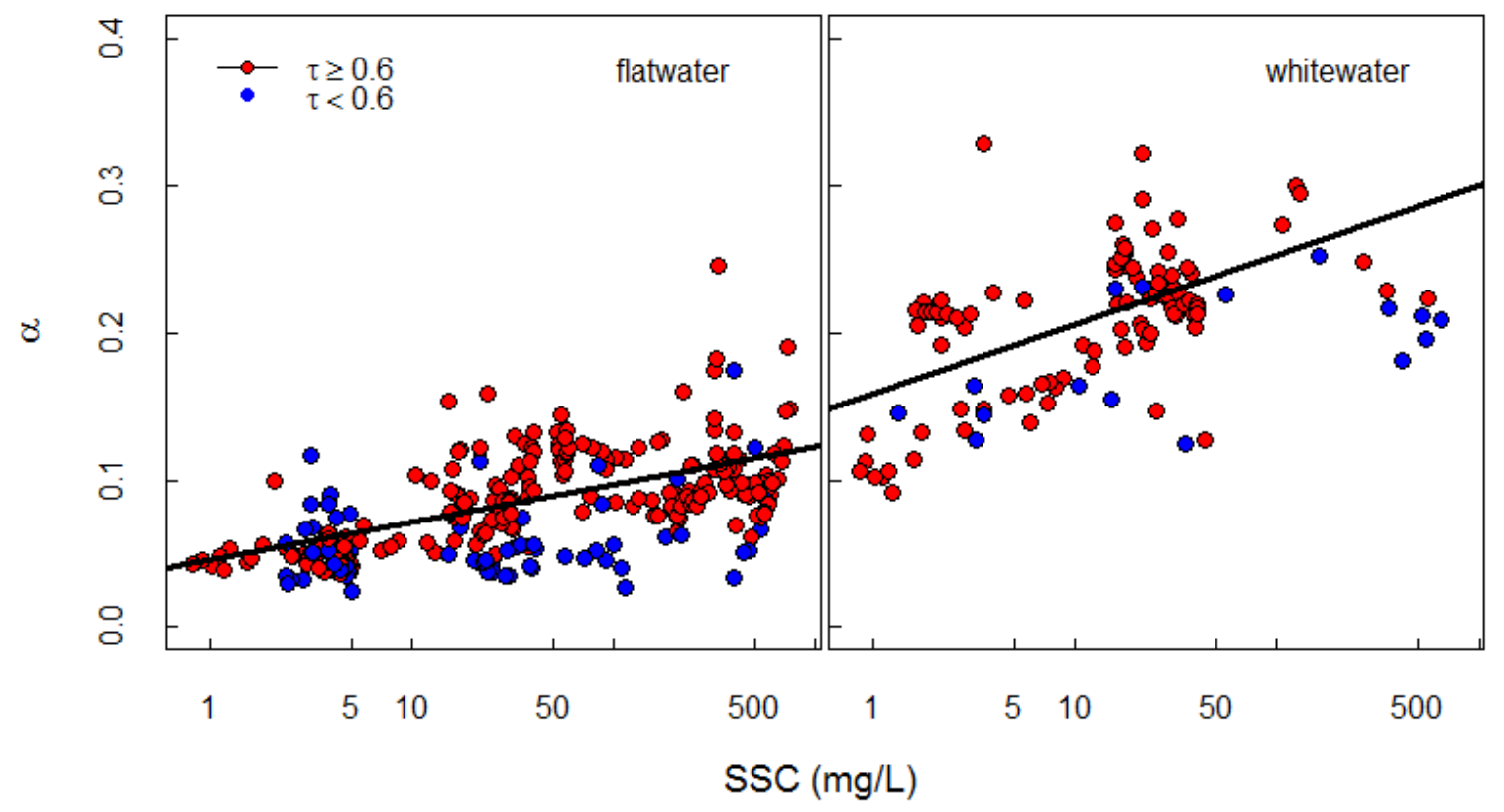

Figure 3.8: The relation between albedo and $S S C$. Note that the x-axis is plotted on a logarithmic scale. Solid black regression lines are for $\tau \geq 0.6$. 


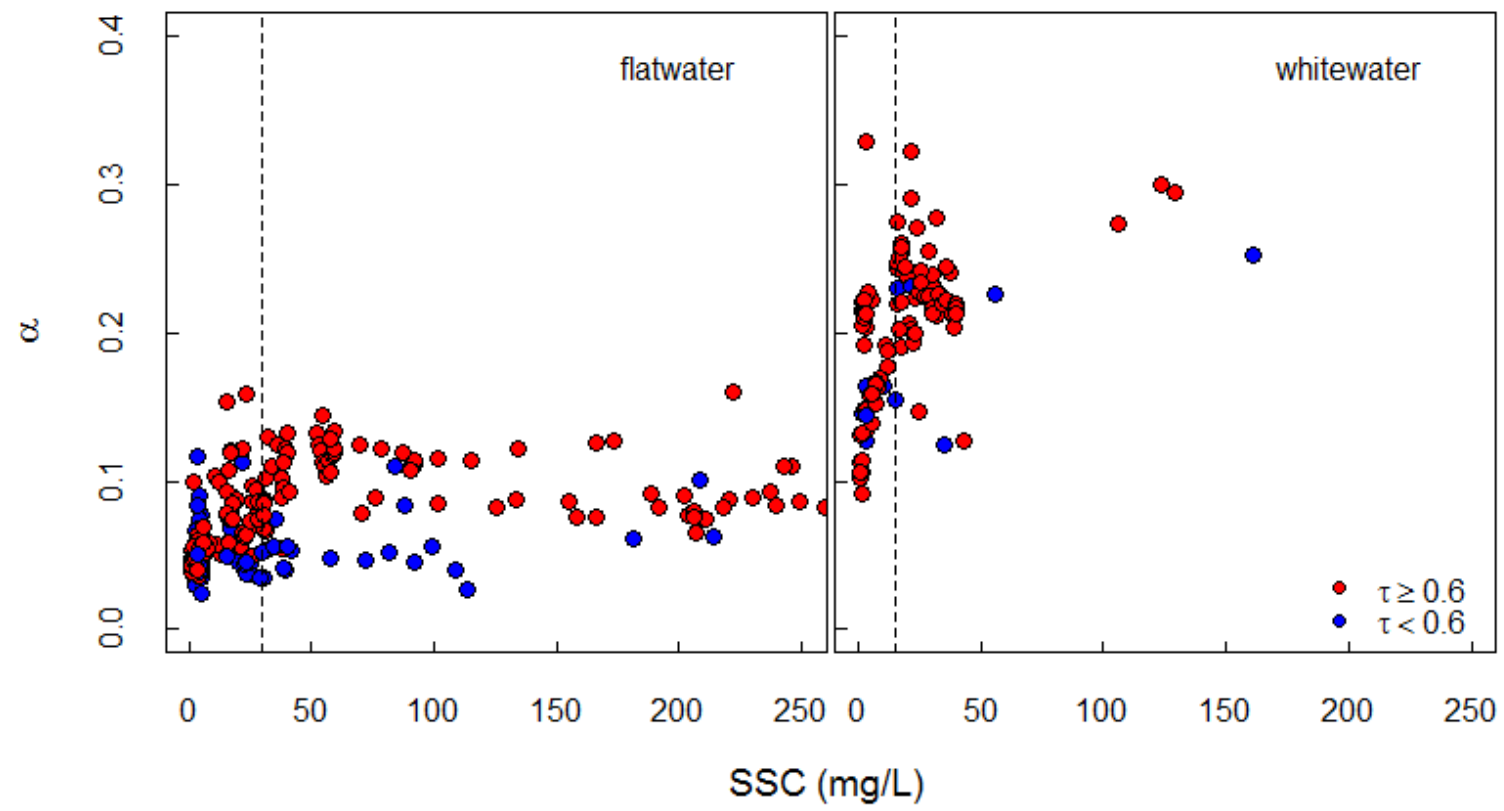

Figure 3.9: The relation between albedo and $S S C$. Note that the x-axis is on a linear scale and truncated at $S S C=250 \mathrm{mg} / \mathrm{L}$. Vertical lines are positioned at $30 \mathrm{mg} / \mathrm{L}$ for the left panel and $15 \mathrm{mg} / \mathrm{L}$ on right panel to highlight differences in the form of the relation at low and high $S S C$.

\subsubsection{Relation with discharge and aeration}

Albedo exhibited a weak positive relation with discharge at the hydraulic jump on Rutherford Creek (Figure 3.10), although the slope of the regression was not significant (slope $=0.018, p=0.127)$. The relation was stratified by solar elevation angle $(h)$ and $S S C$ to assess potential confounding effects. Both high and low SSC measurements were present across the range of measured flows. However, a majority of measurements taken during high flows $\left(Q>2.4 \mathrm{~m}^{3} \mathrm{~s}^{-1}\right)$ were taken at low solar elevation angles $\left(h<40^{\circ}\right)$. The influence of atmospheric transmissivity was minimal, since only 2 of the 54 albedo measurements at the hydraulic jump were measured during diffuse lighting conditions. 


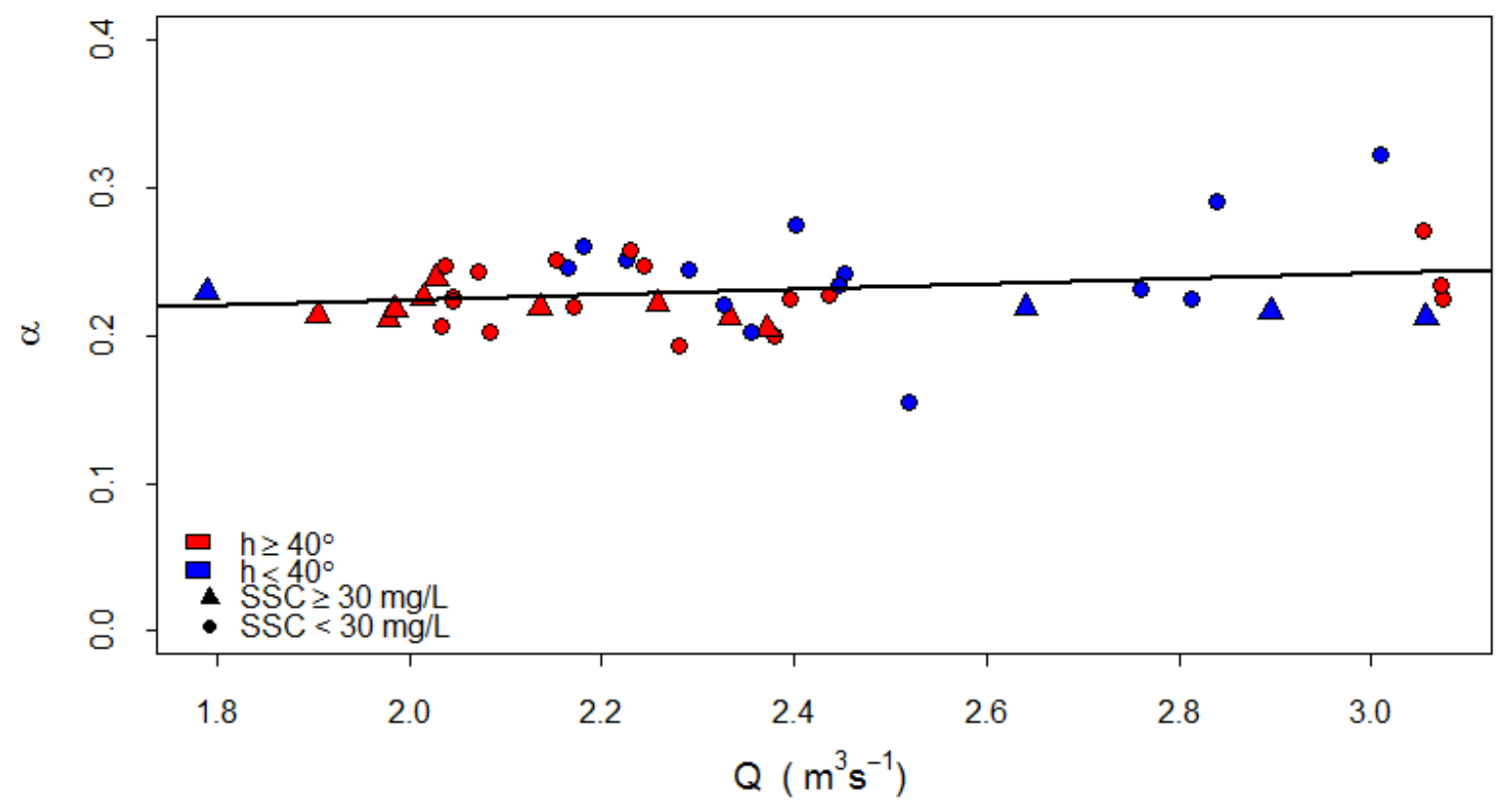

Figure 3.10: Albedo as a function of discharge at Rutherford Creek, stratified by transmissivity and suspended sediment concentration.

\subsubsection{Recursive partitioning}

Regression tree fits to the flatwater and whitewater albedo subsets are displayed in Figures 3.11 and 3.12. For both subsets, $S S C$ was the strongest predictor of albedo. Initial splits occurred at $S S C=30.9 \mathrm{mg} / \mathrm{L}$ for flatwater measurements and at $S S C=$ $15.4 \mathrm{mg} / \mathrm{L}$ for whitewater measurements. For flatwater, subsequent splits were made at $h=37.52^{\circ}$ and $\tau=0.52$. For whitewater, the subsequent split occurred at $S S C=1.61$ $\mathrm{mg} / \mathrm{L}$. No additional splits occurred for whitewater measurements with values of $S S C$ greater than $15.44 \mathrm{mg} / \mathrm{L}$ using $c_{p}=0.4$. 


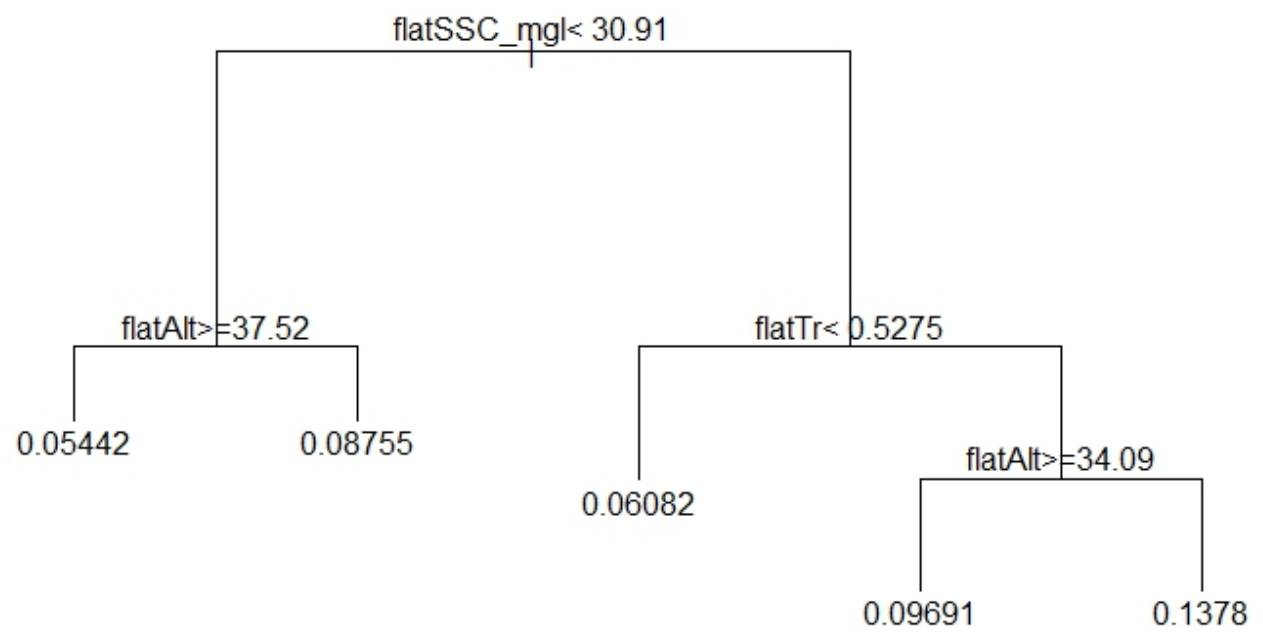

Figure 3.11: Regression tree fit to the flatwater subset. Mean albedo values for the final classes are indicated on the end of each leaf. Variable names in the figure correspond to predictor variables as follows: flatSSC_ $m g l=S S C$ $(\mathrm{mg} / \mathrm{L})$, flatAlt $=h$ (degrees), flat $\mathrm{Tr}=\tau$. 


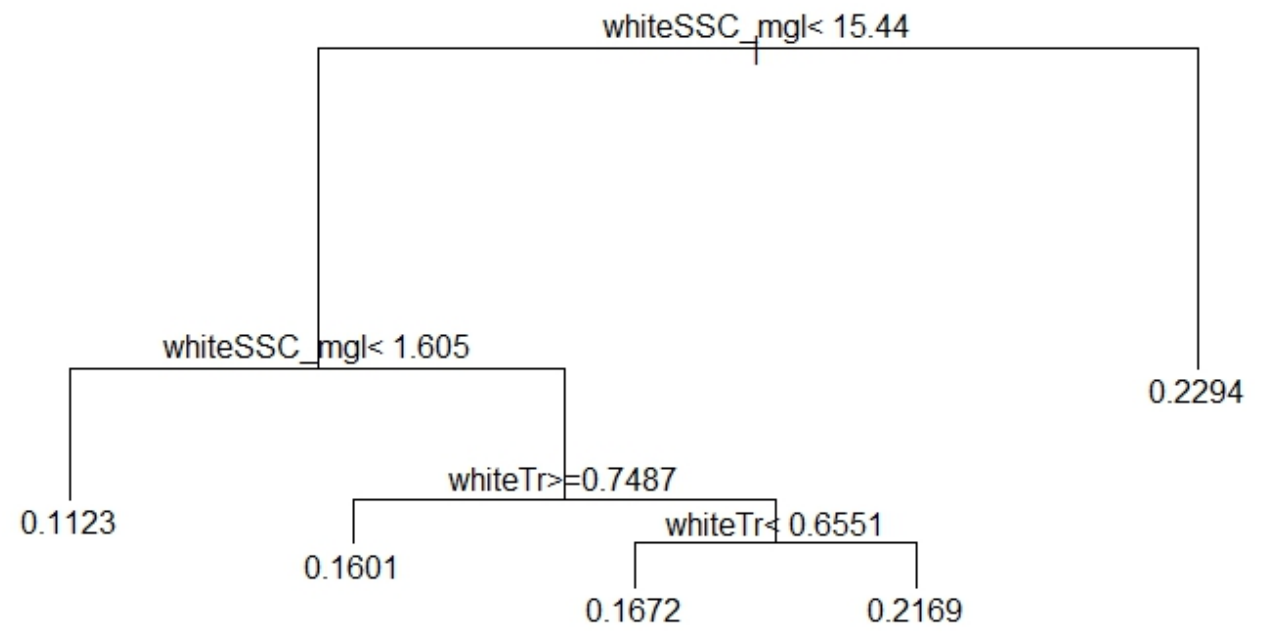

Figure 3.12: Regression tree fit to the whitewater albedo subset. Variable names in the figure correspond to predictor variables as follows: whiteSSC_ mgl $=S S C(\mathrm{mg} / \mathrm{L})$, whiteAlt $=h$ (degrees), white $\operatorname{Tr}=\tau$. 


\subsection{Statistical modelling}

\subsubsection{Model fitting and cross validation}

Tables 3.4 and 3.5 summarize results of the model fitting using the categorical SSC representation. For both flatwater and whitewater subsets, many models, including those with the lowest $\Delta \mathrm{AIC}_{c}$ values, did not have physically reasonable coefficients. Within the flatwater subset, the two models with the highest predictive ability had $S S C$ terms with a negative coefficient for both models, which is not physically realistic. Of the flatwater models with physically reasonable coefficients, models 3 and 4 had the greatest predictive ability. Both explained $60 \%$ of the variance prior to cross-validation. Models 5 and 6 were the only candidate models within the whitewater subset that had physically reasonable coefficients. Model 6 had the highest predictive ability, accounting for $43 \%$ of the variance in albedo.

The model fitting process was repeated using $\ln S S C$ (Table 3.6; Table 3.7). Model 11 has the lowest $\mathrm{AIC}_{c}$ value of all models within the flatwater subset, and accounts for $62 \%$ of variance in albedo. Additionally, all coefficients are physically reasonable for the model. There was also support for model 10 , as evidenced by $\Delta \mathrm{AIC}_{c}$ of 1.875 and plausible coefficients. Within the whitewater subset, only models 12 and 13 had reasonable coefficients.

Model $\mathrm{R}^{2}$ and RMSE following the cross-validation process are displayed in Table 3.8. Within the flatwater subset, models using $\ln S S C$ had higher predictive ability than models that included categorical $S S C$. However, differences in predictive ability in the flatwater candidate models using the same $S S C$ representation were small. Cross validated $\mathrm{R}^{2}$ and RMSE each differ by less than 0.001 between the two flatwater categorical $S S C$ models. The difference was slightly larger for the flatwater $\ln S S C$ models; $\mathrm{R}^{2}$ differed by 0.005 . Whitewater models had higher predictive ability using categorical $S S C$ than with ln $S S C$. Residual distributions varied little between models built for the same subset of albedo and using the same $S S C$ representation, so models were selected on the basis of predictive ability. Since models 3 and 4 were nearly identical in their predictive ability, model 3 was selected for its simplicity. Observed versus predicted values of albedo using the selected models are displayed in Figure 3.13. 
Table 3.4: Summary of model fitting for the flatwater subset. $S S C$ is represented categorically with a threshold at $S S C=30 \mathrm{mg} / \mathrm{L}$. Bold values indicate models where $\Delta \mathrm{AIC}_{c}<2$ compared to the strongest model with physically reasonable coefficients. $\mathrm{S}_{e}=$ standard error of the estimate. Only models with physically reasonable coefficients are displayed in this table and in Tables 3.5-3.7.

\begin{tabular}{ccccccccccc}
\hline & $\Delta \mathrm{AIC}_{c}$ & $\mathrm{Adj} . \mathrm{R}^{2}$ & $\mathrm{~S}_{e}$ & $b_{0}$ & $\sin h$ & $S S C$ & $\tau$ & $\sin h \cdot S S C$ & $\sin h \cdot \tau$ & $S S C \cdot \tau$ \\
\hline 1 & 16.724 & 0.574 & 0.022 & 0.121 & -0.119 & 0.026 & 0.043 & & & \\
2 & 18.716 & 0.572 & 0.022 & 0.119 & -0.115 & 0.030 & 0.043 & -0.006 & & \\
$\mathbf{3}$ & $\mathbf{0 . 0 0 0}$ & $\mathbf{0 . 6 0 0}$ & $\mathbf{0 . 0 2 1}$ & $\mathbf{0 . 0 4 3}$ & $\mathbf{- 0 . 0 0 9}$ & $\mathbf{0 . 0 2 6}$ & $\mathbf{0 . 1 7 3}$ & & $\mathbf{- 0 . 1 8 2}$ & \\
$\mathbf{4}$ & $\mathbf{1 . 9 1 5}$ & $\mathbf{0 . 5 9 9}$ & $\mathbf{0 . 0 2 1}$ & $\mathbf{0 . 0 4 5}$ & $\mathbf{- 0 . 0 1 2}$ & $\mathbf{0 . 0 2 0}$ & $\mathbf{0 . 1 7 4}$ & $\mathbf{0 . 0 0 8}$ & $\mathbf{- 0 . 1 8 5}$ & \\
\hline
\end{tabular}

Table 3.5: Summary of model fitting for the whitewater subset using the categorical representation of $S S C$ with a threshold of $S S C=15 \mathrm{mg} / \mathrm{L}$.

\begin{tabular}{|c|c|c|c|c|c|c|c|c|c|}
\hline & $\Delta \mathrm{AIC}_{c}$ & Adj. $R^{2}$ & $\mathrm{~S}_{e}$ & $b_{0}$ & $\sin h$ & $S S C$ & $\tau$ & $S S C \sin h \cdot \tau$ & $S S C \cdot \tau$ \\
\hline 5 & 0.663 & 0.419 & 0.036 & 0.218 & -0.117 & 0.049 & 0.058 & & \\
\hline 6 & 0.000 & 0.428 & 0.036 & 0.256 & -0.119 & 0.001 & 0.006 & & 0.069 \\
\hline
\end{tabular}

Table 3.6: Summary of model fitting for the flatwater subset using $\ln S S C$ as a predictor variable.

\begin{tabular}{ccccccccccc}
\hline & $\Delta \mathrm{AIC}_{c}$ & $\mathrm{Adj} . \mathrm{R}^{2}$ & $\mathrm{~S}_{e}$ & $b_{0}$ & $\sin h$ & $\ln S S C$ & $\tau$ & $\sin h \cdot \ln S S C$ & $\sin h \cdot \tau \ln S S C \cdot \tau$ \\
\hline 7 & 23.545 & 0.581 & 0.022 & 0.156 & -0.114 & 0.007 & 0.042 & & & \\
8 & 16.647 & 0.592 & 0.022 & 0.187 & -0.158 & 0.018 & 0.041 & -0.015 & & \\
9 & 13.227 & 0.597 & 0.022 & 0.092 & -0.025 & 0.007 & 0.148 & & -0.148 & \\
$\mathbf{1 0}$ & $\mathbf{1 . 8 7 5}$ & $\mathbf{0 . 6 1 5}$ & $\mathbf{0 . 0 2 1}$ & $\mathbf{0 . 1 5 4}$ & $\mathbf{- 0 . 1 6 5}$ & $\mathbf{0 . 0 1 0}$ & $\mathbf{0 . 0 9 6}$ & $\mathbf{- 0 . 0 1 7}$ & & $\mathbf{0 . 0 1 4}$ \\
$\mathbf{1 1}$ & $\mathbf{0 . 0 0 0}$ & $\mathbf{0 . 6 1 9}$ & $\mathbf{0 . 0 2 1}$ & $\mathbf{0 . 1 1 7}$ & $\mathbf{- 0 . 1 0 6}$ & $\mathbf{0 . 0 0 9}$ & $\mathbf{0 . 1 5 0}$ & $\mathbf{- 0 . 0 1 4}$ & $\mathbf{- 0 . 0 8 6}$ & $\mathbf{0 . 0 1 2}$ \\
\hline
\end{tabular}


Table 3.7: Summary of model fitting for the whitewater subset using ln $S S C$ as a predictor variable.

\begin{tabular}{cccccccccc}
\hline & $\Delta \mathrm{AIC}_{c}$ & $\mathrm{Adj} . \mathrm{R}^{2}$ & $\mathrm{~S}_{e}$ & $b_{0}$ & $\sin h$ & $\ln S S C$ & $\tau$ & $\sin h \cdot \ln S S C \sin h \cdot \tau \ln S S C \cdot \tau$ \\
\hline $\mathbf{1 2}$ & $\mathbf{1 . 6 8 6}$ & $\mathbf{0 . 3 5 2}$ & $\mathbf{0 . 0 3 8}$ & $\mathbf{0 . 2 9 9}$ & $\mathbf{- 0 . 1 2 1}$ & $\mathbf{0 . 0 1 3}$ & $\mathbf{0 . 0 7 3}$ & \\
$\mathbf{1 3}$ & $\mathbf{0 . 0 0 0}$ & $\mathbf{0 . 3 6 8}$ & $\mathbf{0 . 0 3 8}$ & $\mathbf{0 . 2 6 4}$ & $\mathbf{- 0 . 1 1 5}$ & $\mathbf{0 . 0 0 2}$ & $\mathbf{0 . 1 2 5}$ & \\
\hline
\end{tabular}

Table 3.8: Cross-validated $\mathrm{R}^{2}$ and RMSE for models selected during the initial stages of model fitting. FW and WW indicate whether the model is for flatwater or whitewater conditions. Bold indicates final selected models.

\begin{tabular}{|c|c|c|c|}
\hline & Model & $\mathrm{R}^{2}$ & RMSE \\
\hline & FW $\sin +S S C+\tau+(\sin h \cdot \tau)$ & 0.597 & 0.023 \\
\hline 4 & $\mathrm{FW} \sin h+S S C+\tau+(\sin h \cdot S S C)+(\sin h \cdot \tau)$ & 0.597 & 0.024 \\
\hline 5 & $\mathrm{WW} \sin h+S S C+\tau$ & 0.413 & 0.061 \\
\hline 6 & $\mathbf{W W} \sin h+S S C+\tau+(S S C \cdot \tau)$ & 0.422 & 0.061 \\
\hline 10 & $\mathrm{FW} \sin h+\ln S S C+\tau+(\sin h \cdot \ln S S C)+(\ln S S C \cdot \tau)$ & 0.615 & 0.023 \\
\hline 11 & $\mathrm{FW} \sin h+\ln S S C+\tau+(\sin h \cdot \ln S S C)+(\sin h \cdot \tau)+(\ln S S C \cdot \tau)$ & 0.620 & 0.023 \\
\hline 12 & $\mathrm{WW} \sin h+\ln S S C+\tau$ & 0.360 & 0.064 \\
\hline 13 & $\mathrm{WW} \sin h+\ln S S C+\tau+(\ln S S C \cdot \tau)$ & 0.373 & 0.065 \\
\hline
\end{tabular}

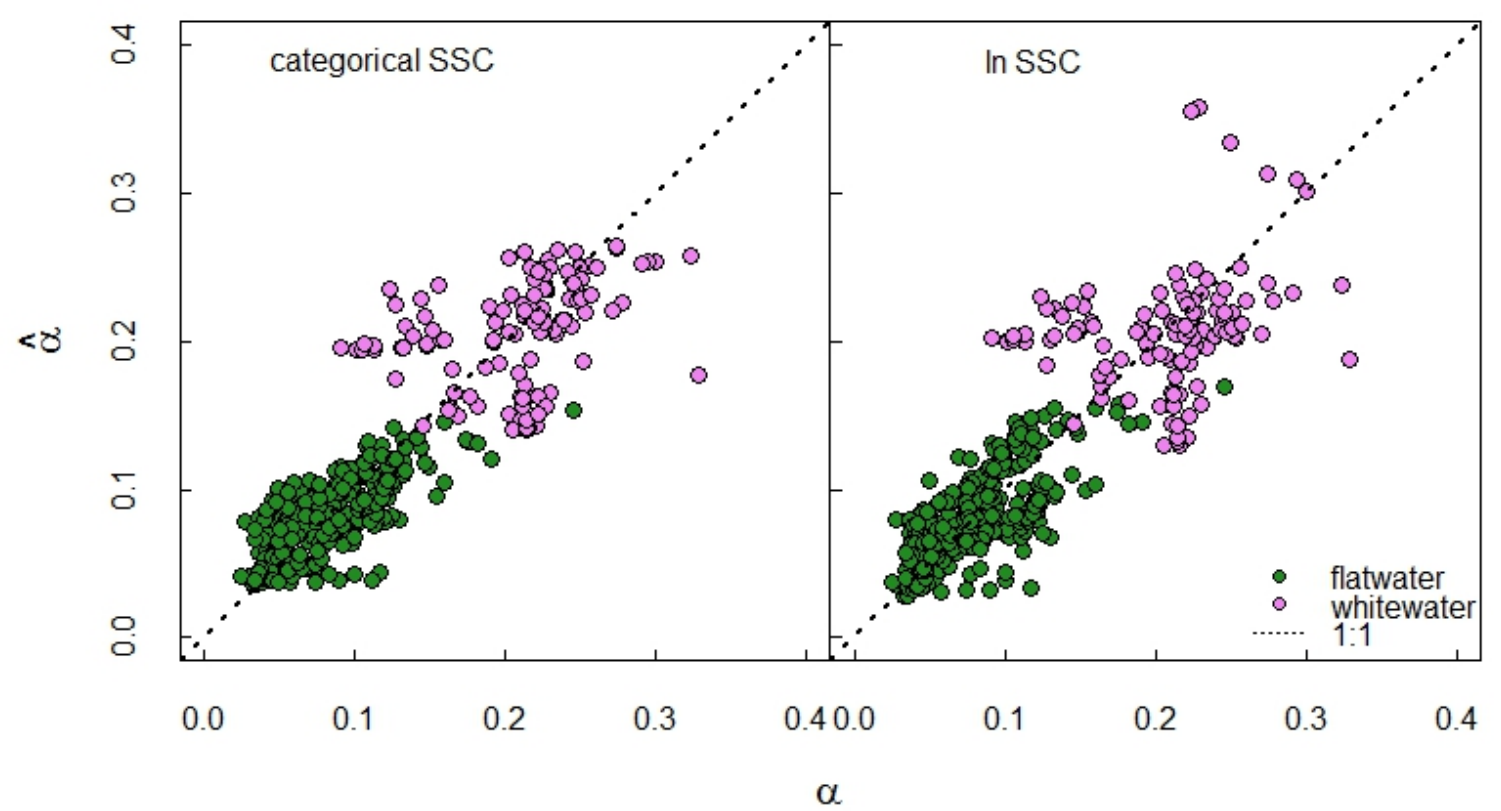

Figure 3.13: Cross-validated predicted albedo values versus observed albedo for the flatwater and whitewater subsets. The left-hand panel shows results with $S S C$ represented as a binary variable (low/high) and the right-hand panel shows results with $\ln S S C$ as a predictor variable 


\section{Chapter 4}

\section{Discussion}

\subsection{Analysis of albedo variability}

\subsubsection{Solar angle and transmissivity}

Albedo exhibited large diurnal swings in magnitude during clear sky conditions. Differences between maximum and minimum albedo values observed in direct lighting conditions averaged by reach were 0.12 for both flatwater and whitewater locations. The maximum flatwater albedo value measured on the lower Lillooet reach was 0.25 , measured at a solar elevation angle of $13.9^{\circ}$. Measured values of albedo at given solar elevation angles were similar to those reported in ocean and lake surface. For example, Payne (1972) reported a diurnal pattern in albedo that was similar in magnitude to those in this study, including comparable values at low solar elevation angles.

The latitude and high relief of the study area restricted the range of angles that direct solar radiation could be measured from. Horizon angles throughout the study area averaged $25^{\circ}$ in the west and southwest directions, and were consistently above $10^{\circ}$, imposing a lower limit on the range of elevation angles. The highest elevation angle possible for the sites (at solar noon on the summer solstice) is $63.1^{\circ}$, and the highest elevation angle during an albedo measurement was $62.8^{\circ}$. As a result of these limits, some patterns of variability were not observed that may affect streams at lower latitudes or in lowland regions. For example, albedo values approaching unity have been observed on calm surfaces as the sun approaches $0^{\circ}$ at sunrise or sunset

The interaction between transmissivity and solar elevation angle matched the expected pattern of variability described by Katsaros et al. (1985) and Oke (1987) for flatwater conditions. Diffuse lighting conditions (low transmissivity) were associated with 
reduced surface albedo across the range of calculated solar elevation angles. The largest reduction of albedo during diffuse light conditions occurred at low elevation angles when the sun was near the horizon. However, diffuse lighting conditions appeared to have minimal influence on whitewater albedo at high elevation angles. The apparent lack of response may reflect the fact that aeration would create a broad range of incidence angles, even for direct solar radiation, in contrast to flatwater. However, the apparent lack of response could also result from suspended sediment bias. SSC measurements corresponding to whitewater albedo measurements taken at solar elevations greater than $45^{\circ}$ in direct light conditions averaged $22 \mathrm{mg} / \mathrm{L}$, whereas average $S S C$ for whitewater albedo in the same conditions was $81 \mathrm{mg} / \mathrm{L}$. The suppressed response of albedo to solar altitude under diffuse lighting conditions also explains the reduction in variance in albedo, since values are reduced the most at low solar elevation angles. Diffuse lighting conditions should create the greatest reduction in albedo at low solar elevation angles when albedo values are highest during clear-sky conditions, which would reduce the amount of variance in the relation between albedo and elevation angle.

\subsubsection{Discharge and aeration}

A primary objective of this study was to quantify the influence of aeration on stream surface albedo. At Rutherford Creek, albedo measurements were taken at three locations that encompassed a range of visible levels of aeration. Average albedo values at the three sites were 0.09, 0.13, and 0.22, respectively. Subsequent albedo measurements taken at calm and aerated portions of the stream surface several metres apart from each other on Rutherford Creek and Rubble Creek differed by 0.14, on average. These findings indicate that, controlling for the effects of solar elevation angle and transmissivity, aeration significantly enhances albedo.

The relation between albedo and discharge was weak. The weak response of stream surface albedo to aeration with increasing flow can likely be attributed in part to the height of the pyranometers above the stream surface during measurements as well as the range of flow conditions experienced at Rutherford Creek during the field season. Measured flows during sampling campaigns on Rutherford Creek only ranged between 1.8 and $3.1 \mathrm{~m}^{3} \mathrm{~s}^{-1}$, reflecting the diversion of flow around the sampling reach for a runof-river hydroelectric facility. Albedo measurements at the hydraulic jump were taken at a height of approximately $0.5 \mathrm{~m}$ in order to minimize the pyranometer's view of boulders and to consistently view aerated portions of the surface, as opposed to viewing a combination of visibly aerated and calm portions of the water surface that would vary with discharge. In contrast, Richards and Moore (2011) measured albedo over 
a broader range of flows, ranging from approximately 0.5 to $7.0 \mathrm{~m}^{3} \mathrm{~s}^{-1}$. Furthermore, their downward-facing pyranometer was at a greater height above the surface than in the current study (1 $\mathrm{m}$ at low flow), so it sampled a larger area with varying degrees of aeration, which in turn varied with discharge, contributing to a stronger relation between albedo and discharge.

Reflectance increases in visible wavelengths as the thickness of foam increases (Whitlock et al., 1982), suggesting that increasingly thick layers of foam should increase albedo after the entirety of the pyranometer's field of view is covered by whitewater. Despite whitewater covering almost all of the pyranometer's field of view during whitewater measurements at Rutherford Creek, the highest albedo value measured was 0.32 , which is below the maximum value of 0.4 measured by Richards and Moore (2011), and 0.5 measured by Whitlock et al. (1982), suggesting that albedo could continue to increase with aeration at higher discharges at the hydraulic jump. Highly aerated flow over cascades, where albedo values were likely to be higher than 0.32 , were present at Rubble Creek; however, the most vigorously aerated portions of flow were inaccessible and thus were not sampled.

One issue that is difficult to address is the location-specific relation between aeration and discharge. For instance, the rate at which flow becomes visibly aerated with increasing discharge may differ between riffles and hydraulic jumps downstream of rock steps. Additionally, stream surface albedo varies widely on a fine spatial scale in channels with complex morphologies. Therefore, it may be most effective to determine the relationship between albedo and aeration in terms of areal increases to visible whitewater at higher flows to account for aeration effects.

\subsubsection{Suspended sediment}

Stream surface albedo varied with suspended sediment concentration (Table 3.3). Albedo in streams with low suspended sediment concentrations $(S S C<50 \mathrm{mg} / \mathrm{L}$ ) averaged 0.06 , which is comparable with the values found in studies on low-gradient streams with low SSC (e.g Evans et al., 1998; Leach and Moore, 2010). Other studies have reported average daily albedo values as low as 0.03 (Caissie et al., 2007; Benyahya et al., 2012), which were lower than almost all clear-sky albedo values measured in this study. Only three measured albedo values in this study were less than 0.03; all three were measured under overcast conditions.

Measured albedo values for streams with higher suspended sediment concentration were similar to values found in past work from high-turbidity settings. Mean albedo values for streams with $S S C$ greater than $50 \mathrm{mg} / \mathrm{L}$ averaged 0.10 , which is consistent 
with the values reported by Chikita et al. (2010) on a highly turbid proglacial river where $S S C$ typically exceeded $200 \mathrm{mg} / \mathrm{L}$. Measurements from Lillooet River were nearly identical to those found in previous work by Knudson (2012) on the same river. Nielson et al. (2009) also reported an increase of 0.03 to 0.07 in albedo with turbidity. Average flatwater albedo measured in this study with corresponding $S S C>50 \mathrm{mg} / \mathrm{L}$ was 0.04 higher than measurements with $S S C<50 \mathrm{mg} / \mathrm{L}$.

Albedo increased sharply with $S S C$ at low concentrations and flattened at high concentrations for both flatwater and whitewater conditions. This nonlinear dependence of albedo on SSC is not surprising; a similar relation was observed by Han (1997) within visible wavelengths in a laboratory setting. The strong positive relation between albedo and $S S C$ visibly began to flatten as sediment concentrations approached $30 \mathrm{mg} / \mathrm{L}$ in flatwater and $15 \mathrm{mg} / \mathrm{L}$ in whitewater. Consistent with these visual observations, primary splits in the recursive partitioning analysis were at $30.91 \mathrm{mg} / \mathrm{L}$ for flatwater and $15.44 \mathrm{mg} / \mathrm{L}$ for whitewater.

The saturation effect in the relation may be explained by enhancement of albedo by backscatter that would decrease at higher concentrations of suspended sediment (Nunez et al., 1972; Katsaros et al., 1985), since backscatter has been reported to be higher in clear water than highly turbid water (Jerlov, 1968).

\subsection{Model performance}

\subsubsection{Model selection and testing}

Models fit for flatwater albedo had greater predictive ability than those for whitewater conditions. The weaker predictive ability of the whitewater models reflects the increased scatter in the relation brought on by aeration that was not accounted for by any terms in the model. Surface roughness at low solar elevation angles at aerated locations may have also contributed to scatter (Oke, 1987), particularly at hydraulic jumps where albedo tended to be largest in magnitude.

The majority of the models considered during the initial stages of model fitting did not have reasonable coefficients and were thus rejected. Considering the cross-validation performance and the physical reasonableness of the model coefficients, three models are recommended. Two flatwater models, models 3 and 11, were selected, using each representation of $S S C$ (categorical and continuous), as well as one whitewater model (model 6 ) using the categorical $S S C$ representation. For flatwater, model 3 (continuous $S S C$ ) slightly outperformed model 11 (categorical $S S C$ ). However, the categorical representa- 
tion is useful because the model can be used even in the absence of suspended sediment data for streams that can visibly be classed as turbid. Model 6 had greater predictive ability using a categorical $S S C$ term than model 13, which used continuous $S S C$ as a predictor. Moreover, model 6 requires less input data.

\subsubsection{Model scaling}

The models developed here address variability in albedo with respect to the governing physical processes, but are based on measurements from isolated points on the water

surface. As demonstrated at Rubble Creek, Cayoosh Creek, and Rutherford Creek, the value of albedo can vary widely on a scale of metres. Measurements from a single point or several points on the stream surface do not necessarily represent the entire stream surface, since variability in albedo is continuous both temporally and spatially across the stream surface.

Spatial variability could be addressed to some extent by sampling albedo at a greater number of points along the stream surface and calculating an average value for the reach in question. Temporal variability due to solar elevation angle is already accounted for by the model. However, stream surface shading derived from vegetation, topography, streambanks, and cloud cover varies both spatially and temporally, influencing the fractions of direct and diffuse solar radiation (and thus the albedo). Future work should explore methods of upscaling albedo measurements to represent the full stream surface and investigate the effectiveness of point measures compared to a more complete wholesurface representation of albedo.

\subsection{Analysis of digital camera images}

The magnitude of scatter in the relation between albedo and the coefficient of variation within the photographs was comparable in proportion to the measured albedo values, limiting the utility of the relation as a predictor of albedo. However, the form of the relation between albedo and $C V$ is reasonable. The fit of the observations to a logistic function supports the assertion that albedo increases with $C V$ as the surface becomes more visibly aerated, and that the relation should flatten at high amounts of aeration as images become increasingly white as they are saturated with light-coloured pixels. 
Much of the noise in the relation may be inherent to the changing appearance of the water surface from moment to moment. Flow crossing beneath the camera may not have the same appearance and $C V$ from second to second, particularly over rock- or logsteps or cascades where localized water velocity is high. Further, solar elevation angle, atmospheric transmissivity, and $S S C$ influence albedo independently from aeration, thus representing additional confounding influences and sources of scatter. 


\section{Chapter 5}

\section{Conclusion}

\subsection{Key findings}

Due to its dependence on the incidence angle for direct solar radiation, albedo exhibited a strong diurnal cycle in clear weather conditions that is consistent with patterns of variability reported in ocean and lake studies (Nunez et al., 1972; Payne, 1972; Oke, 1987). Albedo values measured in conditions dominated by direct radiation ranged from 0.04 to 0.25 in flatwater and 0.09 to 0.33 in whitewater, so characterizing stream albedo using individual albedo measurements may not be appropriate, especially in streams that are exposed to direct solar radiation at a range of solar elevation angles. Albedo tended to decrease with increasing diffuse radiation, especially at low solar angles, consistent with optical theory (Katsaros et al., 1985; Oke, 1987).

Albedo was enhanced at sites with visible whitewater: at Rutherford Creek, albedo averaged 0.09 over calm surfaces and 0.22 over aerated surfaces. The observed weak response of albedo to increasing discharge and aeration was potentially limited by the narrow range of flows that were sampled during the field season. Also, it is likely that albedo exhibits a stronger response to discharge when averaged over larger areas of the stream surface, as found by Richards and Moore (2011).

Albedo increased sharply with $S S C$ at low concentrations and then levelled out at higher concentrations. Recursive partitioning analysis of the albedo- $S S C$ relation suggested thresholds of $30 \mathrm{mg} / \mathrm{L}$ in flatwater and $15 \mathrm{mg} / \mathrm{L}$ over flatwater. Compared to low $S S C$ conditions, average values of albedo were enhanced by 0.04 for $S S C \geq 30 \mathrm{mg} / \mathrm{L}$ over flatwater, and by 0.06 for $S S C \geq 15 \mathrm{mg} / \mathrm{L}$ over whitewater.

Predictive models were fit separately for flatwater and whitewater using regression analysis, with candidate predictors including the sine of the solar elevation angle, trans- 
missivity and suspended sediment concentration, and their interactions. Candidate models were tested through cross-validation between study reaches, and models with physically unrealistic coefficients were rejected. For flatwater, use of $\ln S S C$ as a predictor yielded the highest predictive capability; predictive ability decreased slightly using a categorical representation of $S S C$. However, the model incorporating $S S C$ as a categorical variable (low/high) offers the advantage of allowing the user to make predictions in the absence of suspended sediment data. For whitewater, the categorical $S S C$ representation yielded superior predictive ability compared to the inclusion of $\ln S S C$ into the model.

The coefficient of variation of digital camera images was tested as a proxy for albedo in relation to aeration. The albedo- $C V$ relation approximated a logistic curve, suggesting that the positive relation between albedo and $C V$ flattens as images become more visibly white as light-coloured pixels saturate the image at high flows. Unfortunately, the magnitude of scatter in the relation is comparable to the range of measured albedo values, limiting the utility of the relation as a predictor.

\subsection{Recommendations for future research}

This study has quantified the dependence of albedo on the controlling physical processes for mountain streams encompassing a broad range of conditions and developed statistical models to predict stream surface albedo. The statistical models were tested through cross validation, but should be evaluated over a broader range of conditions. In particular, the range of solar elevation angles sampled was limited by the high relief of the study sites and by the latitude and dates of sampling. Therefore, the predictive models should be further tested at sites that experience both lower and higher solar elevation angles than sampled here. In this study, only suspended sediment concentration was considered, whereas the effect of suspended sediment on albedo could also be influenced by mineralogy or particle size distribution.

Stream surface albedo varies both spatially and temporally across the stream surface. Measurements of albedo, including those in this study, have been measured at isolated points over the stream surface that may not be representative of the overall albedo of the stream surface. Future work should consider methods for upscaling these existing point models or developing alternative models that account for whole-surface albedo.

The relation between albedo and discharge found in this study was weak and thus not incorporated into the whitewater albedo models. Further, the relation between albedo and discharge is location-specific and may vary on a fine spatial scale. In order to address spatial complexities in the discharge-aeration relation and to increase the predictive 
ability of the whitewater albedo models, future work should continue to investigate the relationship between albedo and aeration as a function of streamflow and channel morphology (e.g., slope, bed roughness, hydraulic geometry). 


\section{Bibliography}

Anderson, E. R. Water-loss investigations: Lake Hefner studies. Technical Report 269, United States Geological Survey, 1954.

Bartholow, J. M. A modeling assessment of the thermal regime for an urban sport fishery. Environmental Management, 15(6):833-845, 1991.

Benyahya, L., Caissie, D., Satish, M. G., and El-Jabi, N. Long-wave radiation and heat flux estimates within a small tributary in Catamaran Brook (New Brunswick, Canada). Hydrological Processes, 26:475-484, 2012. doi:10.1002/hyp.8141.

Boyd, M. and Kasper, B. Analytical methods for dynamic open channel heat and mass transfer: methodology for heat source model Version 7.0. Technical report, Watershed Sciences, Inc., 2003. URL http://www.deq. state.or.us/wq/tmdls/docs/tools/heatsourcemanual.pdf.

Caissie, D. The thermal regime of rivers: a review. Freshwater Biology, 51:1389-1406, 2006. doi:10.1111/j.1365-2427.2006.01597.x.

Caissie, D., Satish, M. G., and El-Jabi, N. Predicting water temperatures using a deterministic model: application on Miramichi River catchments (New Brunswick, Canada). Journal of Hydrology, 336:303-315, 2007.

doi:10.1016/j.jhydrol.2007.01.008.

Chikita, K. A., Kaminaga, R., Kudo, I., Wada, T., and Kim, Y. Parameters determining water temperature of a proglacial stream: the Phelan Creek and the Gulkana Glacier, Alaska. River Research and Applications, 26:995-1004, 2010. doi:10.1002/rra.1311.

Coutant, C. Perspective on temperature in the Pacific Northwest's fresh water. Technical report, Oak Ridge National Laboratory, Oak Ridge, Tennessee, 1999.

Dymond, J. R. Water temperature change caused by abstraction. Journal of Hydraulic Engineering, 110(7):987-991, 1984.

Elliott, J. M. and Hurley, M. A. A functional model for maximum growth of Atlantic Salmon parr, Salmo salar, from two populations in northwest England. Functional Ecology, 11:592-603, 1997. 
Evans, E. C., McGregor, G. R., and Petts, G. E. River energy budgets with special reference to river bed processes. Hydrological Processes, 12:575-595, 1998.

Fenkes, M., Shiels, H. A., Fitzpatrick, J. L., and Nudds, R. L. The potential impacts of migratory difficulty, including warmer waters and altered flow conditions, on the reproductive success of salmonid fishes. Comparative Biochemistry and Physiology, Part A, 193:11-21, 2016. doi:10.1016/j.cbpa.2015.11.012.

Ficke, A. D., Myrick, C. A., and Hansen, L. J. Potential impacts of global climate change on freshwater fisheries. Reviews in Fish Biology and Fisheries, 17:581-613, 2007. ISSN 09603166. doi:10.1007/s11160-007-9059-5.

Forsythe, G. E., Malcolm, M. A., and Moler, C. B. Computer methods for mathematical calculations. Wiley, 1977. ISBN 0131653326.

Han, L. Spectral reflectance with varying suspended sediment concentrations in clear and algae-laden waters. Photogrammetric Engineering and Remote Sensing, 63(6): 701-705, 1997. ISSN 0099-1112. doi:10.1080/01431169408954353.

Hannah, D. M., Malcolm, I. A., Soulsby, C., and Youngson, A. F. A comparison of forest and moorland stream microclimate, heat exchanges and thermal dynamics. Hydrological Processes, 22:919-940, 2008. doi:10.1002/hyp.

Hudson, R. and Fraser, J. Introduction to salt dilution gauging for streamflow measurement part IV: The mass balance (or dry injection) method. Streamline Watershed Management Bulletin, 9(1):6-12, 2005. doi:10.3189/172756404781814898.

Hughes, N. F. A model of habitat selection by drift-feeding stream salmonids at different scales. Ecology, 79(1):281-294, 1998.

Iqbal, M. An introduction to solar radiation. Academic Press, Toronto, 1983.

Isaak, D. J., Luce, C. H., Rieman, B. E., Nagel, D. E., Peterson, E. E., Horan, D. L., Parkes, S., and Chandler, G. L. Effects of climate change and wildfire on stream temperatures and salmonid thermal habitat in a mountain river network. Ecological Applications, 20(5):1350-1371, 2010.

Jerlov, N. Optical oceanography. Elsevier Ltd, Amsterdam, 1968.

Jin, Z., Charlock, T. P., Smith, W. L. J., and Rutledge, K. A parameterization of ocean surface albedo. Geophysical Research Letters, 31(22):4-7, 2004. ISSN 0094-8276. doi : 10.1029/2004GL021180.

Katsaros, K. B., Mcmurdie, L. A., Lind, R. J., and Devault, J. E. Albedo of a water surface, spectral variation, effects of atmospheric transmittance, sun angle and wind speed. Journal of Geophysical Research, 90:7313-7321, 1985. 
Kido, D., Chikita, K. A., and Hirayama, K. Subglacial drainage system changes of the Gulkana Glacier, Alaska: Discharge and sediment load observations and modelling. Hydrological Processes, 21:399-410, 2007. doi:10.1002/hyp.6364.

Knudson, J. M. The effect of discharge variability on the heat budget and tributary mixing dynamics of a proglacial river. Master's thesis, University of British Columbia, 2012.

Koepke, P. Effective reflectance of oceanic whitecaps. Applied optics, 23(11):1816, 1984. ISSN 0003-6935. doi:10.1364/A0.23.001816.

Leach, J. A. and Moore, R. D. Above-stream microclimate and stream surface energy exchanges in a wildfire-disturbed riparian zone. Hydrological Processes, 24(17): 2369-2381, 2010. ISSN 08856087. doi:10.1002/hyp.7639.

Magnusson, J., Jonas, T., and Kirchner, J. W. Temperature dynamics of a proglacial stream: Identifying dominant energy balance components and inferring spatially integrated hydraulic geometry. Water Resources Research, 48(6):1-16, 2012. ISSN 00431397. doi:10.1029/2011WR011378.

Meier, W., Bonjour, C., Wüest, A., and Reichert, P. Modeling the effect of water diversion on the temperature of mountain streams. Journal of Environmental Engineering, 129(8):755-764, 2003. ISSN 0733-9372. doi:10.1061/(ASCE) 0733-9372(2003) 129:8(755).

Meisner, J. D. Effect of climatic warming on the southern margins of the native range of Brook Trout. Canadian Journal of Fisheries and Aquatic Sciences, 47:1065-1070, 1990.

Moore, R. D., Spittlehouse, D. L., and Story, A. Riparian microclimate and stream temperature response to forest harvesting: A review. Journal of the American Water Resources Association, 7(4):813-834, 2005. ISSN 1093-474X. doi:10.1111/j.1752-1688.2005.tb04465.x.

Neilson, B. T., Stevens, D. K., Chapra, S. C., and Bandaragoda, C. Data collection methodology for a dynamic temperature model testing and corroboration. Hydrological Processes, 23:2902-2914, 2009. doi:10.1002/hyp.7381.

Nunez, M., Davies, J. A., and Robinson, P. J. Surface albedo at a tower site in Lake Ontario. Boundary-Layer Meteorology, 3:77-86, 1972.

Oke, T. Boundary layer climates. Routledge, New York, 2nd edition, 1987.

Olden, J. D. and Naiman, R. J. Incorporating thermal regimes into environmental flows assessments: modifying dam operations to restore freshwater ecosystem integrity. Freshwater Biology, 55:86-107, 2010. doi:10.1111/j.1365-2427.2009.02179.x.

Payne, R. E. Albedo of the sea surface, 1972. ISSN 0022-4928. 
Reeves, G. H., Everest, F. H., and Hall, J. D. Interactions between the Redside Shiner (Richardsonius balteatus) and the Steelhead Trout (Salmo gairdneri) in western Oregon: the influence of water temperature. Canadian Journal of Fisheries and Aquatic Science, 44(1603 - 1613), 1987.

Richards, J. and Moore, R. D. Discharge dependence of stream albedo in a steep proglacial channel. Hydrological Processes, 25(26):4154-4158, 2011. ISSN 08856087. doi:10.1002/hyp.8343.

Richardson, M. E. Refinement of tracer dilution methods for discharge measurements in steep mountain streams. Master's thesis, University of British Columbia, 2015.

Shelbourn, J., Brett, J., and Shirahata, S. Effect of temperature and feeding regime on the specific growth rate of Sockeye salmon fry (Oncolhynchus nerka), with a consideration of size effect. Journal of the Fisheries Research Board of Canada, 30: 1191-1194, 1973.

Sinokrot, B. A. and Gulliver, J. S. In-stream flow impact on river water temperatures. Journal of Hydraulic Research, 38(5):339-349, 2000. doi : $10.1080 / 00221680009498315$.

Sinokrot, B. A. and Stefan, H. G. Stream temperature dynamics: measurements and modeling. Water Resources Research, 29(7):2299-2312, 1993. ISSN 19447973. doi : 10 . 1029/93WR00540.

Symonds, M. R. E. and Moussalli, A. A brief guide to model selection, multimodel inference and model averaging in behavioural ecology using Akaike's information criterion. Behavioral Ecology and Sociobiology, 65(1):13-21, 2011. ISSN 03405443. doi:10.1007/s00265-010-1037-6.

Thomas, R., Gharrett, J., Carls, M., Rice, S., Moles, A., and Korn, S. Effects of fluctuating temperature on mortality, stress, and energy reserves of juvenile Coho salmon. Transactions of the American Fisheries Society, 115(1):52-59, 1986.

Webb, B. W., Hannah, D. M., Moore, R. D., Brown, L. E., and Nobilis, F. Recent advances in stream and river temperature research. Hydrological Processes, 22: 902-918, 2008. doi:10.1002/hyp.

Whitlock, C. H., Bartlett, D. S., and Gurganus, E. A. Sea foam reflectance and influence on optimum wavelength for remote sensing of ocean aerosols. Geophysical Research Letters, 9(6):719-722, 1982. 